\title{
Understanding In-Silico Approaches to Design Synthetic Antifungal Peptides to Combat Fungal Infections like Mucormycosis
}

\author{
Bajwa $\mathbf{T}^{\mathbf{1}}$ and Sharma $\mathbf{R}^{2 *}$ \\ ${ }^{1}$ Department of Microbial Biotechnology, Panjab \\ University, Chandigarh, India \\ ${ }^{2}$ Chairperson, Department of Microbial Biotechnology, \\ Panjab University, Chandigarh, India \\ *Corresponding author: Rohit Sharma, Chairperson, \\ Department of Microbial Biotechnology, Panjab \\ University, Chandigarh, India
}

Received: September 14, 2021; Accepted: October 19, 2021; Published: October 26, 2021

\begin{abstract}
Antimicrobial peptides are the small sized molecule ranging in size from 2 to $9 \mathrm{kDa}$ with expansive range of antimicrobial activity against bacteria, fungi, viruses etc. They are also used as first line of defense against various pathogens. With the emergence of various fungal infections in the present day and uprising antifungal resistance has made the choice of antifungal drugs very limited, the conventional drugs are slowly becoming ineffective to these fungal pathogens. Researchers have turned to these naturally occurring molecules which represent diverse range of functions and structural features but these naturally occurring peptides exhibit high toxicity, instability and low specificity towards the target which can be combatted by using various in silico and computational approaches to design and modify these AMPs in such a way that their efficiency is increased. In this article, we have specifically focused on Mucormycosis infection because of its high mortality rates and a very few synthetic AMPs have been produced against Mucorales considering the severity of this disease and the rapid surge in Mucormycosis cases emerged in the country. In this paper we will discuss about the present scenario of the disease, AMPs as antifungal therapy, role, classification of antifungal peptides, mechanism of action, advantages and limitations of natural AMPs, important physicochemical properties taken into account while designing synthetic AMPs (SAMPs) and the workflow pipeline to characterize and predict potential synthetic AMPs by using the existing web servers, databases and bioinformatics tools to develop new alternatives of conventional drugs available in the market against fungal infections.
\end{abstract}

Keywords: Antimicrobial resistance; Mucormycosis; Synthetic AMPs (SAMPs); In-silico approaches; Fungal pathogens

\section{Introduction}

There has been a tremendous increase in the cases of Mucormycosis, also called the Black fungus infection caused by Mucorales mold or fungus. In the face of all stupendous advances in the field of antibiotics therapy; the morbidity and mortality remain quite uprising due to invasive fungal infestations. This infection has affected more patients with compromised immunity (presently in Diabetic and Covid-19 patients predominantly) causing an alarming situation and an increased rate of deaths in the country. The drugs used for the treatment of Covid-19 patients are majorly Immunosuppressants, which leads to fungal infections causing blood vessels invasion (angio-invasion) and ultimately cell death, tissue necrosis and fungal-ball formation [1] which is black in color, giving it the name "BLACK FUNGUS".

The species Mucorales which are chiefly recovered from the clinical samples are of the genera Rhizopus, Lichtheimia, and Mucor. Out of these three genera, the most common genus associated with mucormycosis is Rhizopus. Other Zygomycetes genera, such as Apophysomyces, Rhizomucor, Cunninghamella, Saksenaea have less prevalence in comparison with the most frequent clinical isolates being R. arrhizus and R. microsporus [2].
The state caused by rapid proliferation of Mucormycosis infection along with the current Covid-19 pandemic is aggravating across the country, which has led the Union Ministry of Health and Family Welfare to make this infection required by law to be reported to official health authorities as a notifiable disease. The severity of the situation can be seen from the fact that the drug used to treat this infection are of limited choice and are not even in stocks, because in usual times, only limited stocks are maintained. Moreover, the ever rising threat of antifungal resistance to filamentous pathogenic fungi like Scedosporium spp., Fusarium spp. [3], and members of the Mucorales [3] adds to the severity.

The available treatments for humans are restricted to four frontline classes of Antifungal drugs: 1) Polyenes: It disrupts the structure of cell membranes by sequestering the fungal membrane sterol ergosterol. For example: Amphotericin B., 2) 5-Fluorocytosine (5-FC): It's a pyrimidine analog which blocks pyrimidine metabolism, ultimately disrupting DNA synthesis. 3) Echinocandins: It inhibits (1-3)- $\beta$-D-glucan synthase and disrupts cell wall biosynthesis and is one of the newest classes of antifungals. 4) Azoles: It blocks ergosterol biosynthesis through inhibition of lanosterol 14- $\alpha$-demethylase and is the most widely used antifungals at present [4]. 
A sprinkling of few other drugs is also available for adjunctive treatments, for e.g.: 5-flucytosine. [5].

Only a small fraction of the more than five million fungal species can cause infections in humans [6]. The genetic plasticity of these fungal pathogens aid them in relatively rapid adaptation to defiance presented by the host immune system and antifungal therapies.

\section{AMPs as an Antifungal Remedy}

Due to the Emergence of antifungal resistance, an increasing number of immunodeficiency related diseases, use of immunosuppressants with only limited therapeutic options available are triggering the search for novel antifungal alternatives which should be less toxic, targeted and broader antimicrobial spectra, diverse mode of actions against pathogenic fungi, higher efficacy and selectivity (7) compared to the present antifungal therapies available.

Antimicrobial Peptides (AMPs) were first described by Dubos RJ. In 1939, who described it in his studies on a bactericidal agent extracted from a soil named gramicidin from Bacillus brevis and assessed its antibacterial properties against experimental Pneumococcus infections in mice models. A few years later, in 1948, another peptide family named Bacillomycin was isolated from Bacillus subtilis, with low antibacterial effects but remarkable antifungal activity. Later on, various potential therapeutic applications and their role as immunomodulators were described.

Antimicrobial Peptides (AMPs), also known as host defense peptides, are generally positively charged short chain peptides (210 amino acids long) and are predominantly found in a wide variety of life forms from microorganisms to humans. AMPs work by two mechanisms, One, killing microbial pathogens directly, Second, acting by indirectly modulating the host defense systems $[8,9]$.

Due to rapidly increasing drug resistance to conventional antibiotics, various endeavors to rework AMPs into clinical applications are ongoing. Several AMPs are currently in the clinical trial phase [10] as novel microbicides and immunomodulatory pharmacological agents including adjunctive or preventive approaches such as antibodies targeting a virulence factor, probiotics, and vaccines [11]

AMPs display remarkable structural and functional diversity [12] and are also present in virtually all organisms making a wide repertoire of novel alternatives which are yet to be characterized.

\section{Role of Natural AMPs}

AMPs constitute an important component of our Non-adaptive or Innate immunity which is regarded as the first line of defense against invading pathogens and respond in hours compared to adaptive immunity which take even longer. An experimental study was conducted in genetically modified mice lacking the gene which encoded for the mouse analog of the human AMP LL37. It was observed that the susceptibility of cutaneous infection was significantly increased and showed that Cathelicidins are an important native component of innate host defense in mice which provide protection against necrotic skin infection caused by Group A Streptococcus (GAS) indicating the potential role of these AMPs as natural protective barriers and in providing non-adaptive immunity.
The main advantage of the natural AMPs as factors of innate immunity is that they can function without high specificity and memory thus eliminating the problem of self-destruction by a cellular compartmentalization and/or specificity for a microbial target that is absent in the animal host. Thus, self-destruction in this way can be avoided without a complicated mechanism, making it an advantage. It must also be more economical with small effector molecules, eliminating two or more intruders at the same time, rather than having a large and specific effector for each foreign invader.

In mammals, AMPs are present mainly within granules of neutrophils and in secretions from epithelial cells covering skin and mucosal surfaces.

AMPs are produced by 2 basic mechanisms: One is ribosomal translation of mRNA and the other is non-ribosomal peptide synthesis. Non-ribosomal peptides are produced by bacteria predominantly and the ribosomally encoded peptides are produced almost by all life forms from microbes to humans. Among the Non-ribosomal origin peptides, known for several decades are used as antibiotics (e.g., polymyxins and gramicidin S), the ribosomally encoded AMPs have been recognized recently for their important role in innate immunity and therapeutic potential.

AMPs are encoded singly as well as in clusters in a genome and are co-expressed. Their expression can be regulated both at the transcriptional and post-transcriptional levels, and the coordinated transcriptional regulation of AMP genes results in expression and accumulation of more than one AMP at a site [13] AMPs are produced as inactive precursors which require proteolytic cleavage to become active peptides by specific proteases. Their regulation is therefore dependent on the abundance of appropriate proteases along with expression [13].

In multicellular organisms, some AMPs undergo constitutive expression, as inactive precursors they are stored in granules in high concentration and are locally released at the site of infection and inflammation, whereas in case of others the expression is induced in response to pathogen-associated molecular patterns and the cytokines (Lai and Gallo, 2009)

\section{Classification of Antifungal Peptides}

Antifungal Peptides (AFPs) are mainly classified on the mode of action adopted by them in order to perform the antimicrobial action.

\section{Pore forming peptides}

One of the most common and prevalent classes of AFPs found in almost all living forms which show a broad spectrum of antifungal activity and have high toxicity simultaneously in comparison to other AMPs against pathogenic targets [15]. There exist different models which describe the modes of action in which these AFPs work on their target pathogen:

Barrel-stave model: Antimicrobial peptides are known to spontaneously induce transmembrane pores in lipid bilayers under certain conditions in which peptides aggregate together, helices of these peptides act as staves leading to barrel-shaped pore formation.

A study was conducted on a prime clinical antibiotic named Amphotericin B (AmB) who's activity was attributed to membrane 


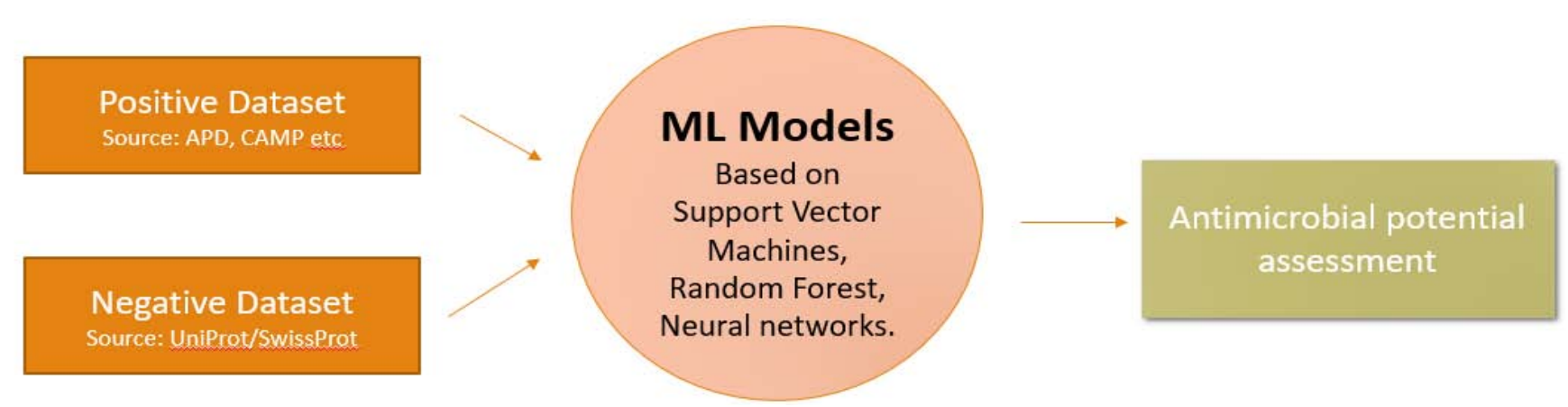

Figure 1: Existing datasets are used to train the Machine learning models to generate predictive and descriptive data to classify AMPs/AFPs based on their family and functional types.

permeabilization occurring after pore formation across the lipid bilayer. Molecular orientation of $\mathrm{AmB}$ was investigated using solidstate NMR to understand the mechanisms involved in antifungal activity and is the only natural peptide with antifungal potential till date [16]. Earlier, there was a notion that fungal pore formation mainly results from ergosterol binding on fungal membranes, resulting in ions leakage ( $\mathrm{K}+$ and $\mathrm{Mg} 2+$ ) and cell death, but a new mechanism which employed physical extraction of ergosterol from lipid bilayer was proven to be mainly responsible for antifungal activity $[17,18]$ Moreover, the production of reactive oxygen species is a universal action process of $\mathrm{AmB}$ against pathogenic yeasts and contributes to the fungicidal activity [19].

Carpet model: Peptides group around in a Carpet like manner due attraction of electrostatic forces. The micelle of peptides touches and coats a small area of the membrane after which the AMP molecules penetrate inside the lipid bilayer to allow pore formation and holes are left behind (Bolintineanu and Kaznessis, 2011). For example, amphipathic dermaseptin peptides, produced by phyllomedusine frog, use Carpet model mechanism and are known to show activity against fungi, viruses, bacteria, protozoa (Bergaoui et al., 2013) Lipopeptides secreted by bacterium Pseudomonas syringae of syringomycin family act by Carpet model of pore formation along with induction of passive ion fluxes, which leads to formation of electrochemical gradient resulting in altered $\mathrm{pH}$ are known to be active against several filamentous fungal and yeast strains including Cryptococcus, Candida strains. Other examples include, dermaseptin-S1 in Candida albicans [23], Cecropins in Insects known to be effective against Aspergillus and Fusarium species by inducing apoptosis followed by disrupted ion fluxes [25].

Toroidal pore model: Perpendicular alignment of AMPs onto the membrane bilayer with their hydrophilic regions and hydrophobic regions facing the pore and associated with the central part of the membrane bilayer respectively. Peptides penetrate into the membrane bilayer resulting pore formation, it also causes formation of toroidal hole by tilting of the lipid bilayer. For example, LL-37 (AMPs in Humans), also called as CRAMPs in mice, produced by neutrophils and cells of innate immune system on epithelial surfaces, where they represent one of the first lines of defense against fungi is an example of this group [26].

LL-37 has a major role in innate immune response [27] as it is known to interact with the carbohydrates of the cell wall and permeabilizes plasma membranes with ROS accumulation [28]. A study was conducted in which the expression of CRAMP was induced which resulted in the reduction in gastrointestinal colonization of Candida albicans and the mortality of mice treated with antibiotics was reduced to 50\% [27]. Another known example is, Protegrins which are cathelicidin related cationic AMPs which work by toroidal pore mechanism and causes $\mathrm{K}+$ ion imbalance, ultimately causing cell death [29,30]. Another compound of this category named Porcine Protegrin-1 (PG-1), is known to show antimicrobial activity against a broad spectrum of drug resistant fungi like Candida species and others like Cryptococcus neoformans, but less effective against Aspergillus species [31].

\section{Membrane active peptides}

Various Antifungal AMPs show antimicrobial activity but their mechanism of actions is unknown whether they kill by forming pores or disintegrate and disrupt membrane integrity by any other unknown mechanism. Here are some examples, Plant defensins are known to possess broad spectrum antifungal activity against various fungi and bacteria [32] and are also speculated to work through Toroidal or carpet model pore formation [33]. Similarly, PvD1 from Phaseolus vulgaris seeds [34], showed fungicidal activity against Fusarium species and Candida species [34] in the strains F. oxysporum, F. solani, F. lateritium and C. albicans, C.tropicalis, C.parapsilosis, and C.guilliermondii respectively [35]. Other plant defensins like DmAMP1 [36] and Pn-AMP1 and Pn-AMP2 [37] also showed antifungal properties possibly due to membrane permeabilization.

Pr-1, a novel AMP from pumpkin rinds showed antifungal potential against Candida species, Fusarium solani, Fusarium oxysporum [38]. Thionins like Capsicum Annuum Thionin (CaThi) exerted permeabilization of membranes in C. parapsilosis, C. albicans and C. tropicalis, where it also induced oxidative stress [39] The intracellular localization of this peptide in C. albicans and C. tropicalis suggested involvement of a possible nuclear target and showed synergistic effect along with fluconazole [39] and the same mechanism was observed in F.solani [40].

Human alpha-defensins HNP-1 and HNP-2 and beta-defensins HBD-1 and HBD-3 defensins are produced by epithelial cells and neutrophils showed characteristic antifungal activity [41] involving different mechanisms. Alpha-defensins work by stimulating efflux of cellular ATP which induce cytotoxicity whereas beta-defensins use an ATP-independent mechanism causing membrane permeabilization 


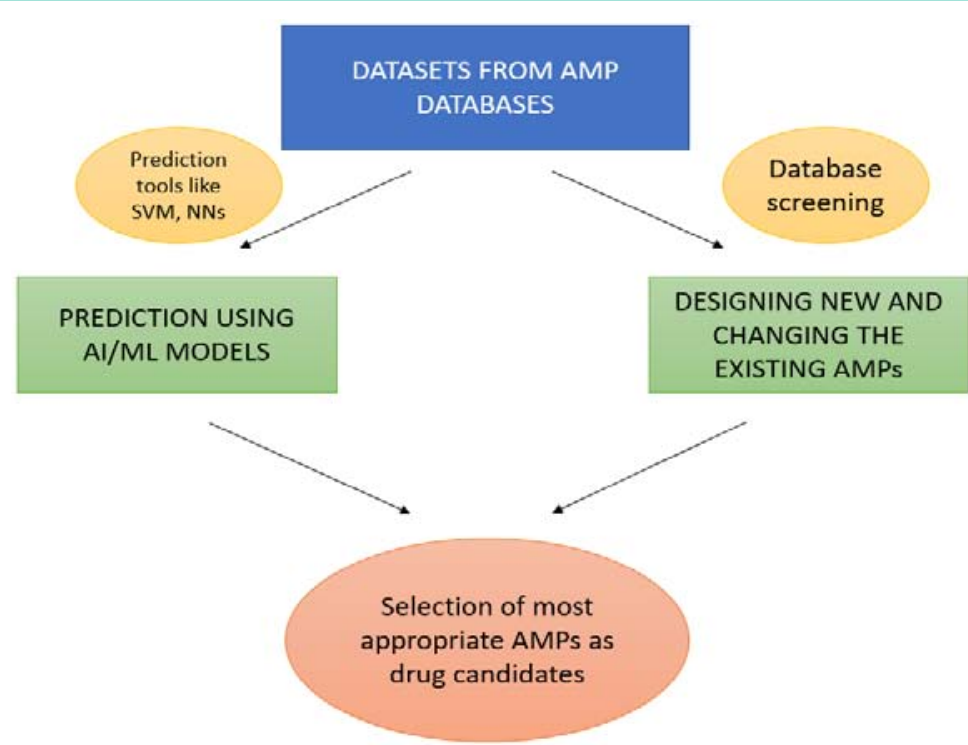

Figure 2: Computational workflow to design AMPs as appropriate drug candidates using Al/ML and other subsets of Artificial Intelligence.

Table 1: Shows the examples of AMPs which show antifungal activity against fungal pathogens and their mode of action.

\begin{tabular}{|c|c|c|c|}
\hline Name of AMP & $\begin{array}{l}\text { Microorganisms against which it shows } \\
\text { antifungal activity }\end{array}$ & Mechanism of Action & References \\
\hline Peptaibols & Trichoderma hypocrea, Emericellopsis, Boletus & Pore forming peptide & [119] \\
\hline Heptaibins & A.fumigatus & Alteration in membrane permeability, pore forming & [120] \\
\hline Cecropins & Aspergillus sp. And Fusarium & Apoptosis and disrupted ion balance & [25] \\
\hline Protegrins & Many Cryptococcus spp., Aspergillus sp. & $\mathrm{K}+$ imbalance $\&$ cell death & [30] \\
\hline LL-37 & Many fungal species & Interact with cell wall carbohydrate, ROS accumulation & [28] \\
\hline Atroviridins & A.niger, F.oxysporum & Alteration in membrane permeability by pore formation & [125] \\
\hline PvD-1 & F.oxysporum, F.solanii & Disrupt membrane integrity & [35] \\
\hline $\begin{array}{l}\text { Human alpha and beta- } \\
\text { defensins }\end{array}$ & Many fungal species & Alteration in membrane permeability & [41] \\
\hline Iturin A & Trichosporon, Fusarium sp., Aspergillus sp. & $\begin{array}{l}\text { Cell wall damage, ROS accumulation, Hog1-MAPKinase } \\
\text { activation }\end{array}$ & [48] \\
\hline Skin PYY & $\begin{array}{l}\text { Arthroderma simii, Trichophyton rubrum, Aspergillus } \\
\text { sp. }\end{array}$ & 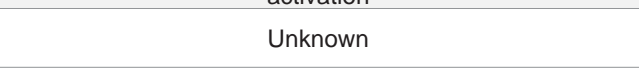 & [126] \\
\hline Aureobasidin & Histoplasma capsulatum, Blastomyces dermatitidis & $\begin{array}{l}\text { Non-competitive inhibition of Inositol phosphoryl ceramide } \\
\text { synthase }\end{array}$ & [51] \\
\hline $\mathrm{HP}(2-20)$ & Trichosporon veigelii & Pore forming & [128] \\
\hline Cm-p1 & T.rubrum, F.oxysporum, A.niger & Pore forming & [53] \\
\hline Echinocandins & Aspergillus sp. & Glucan synthesis inhibitors & {$[73]$} \\
\hline Nikkomycin Z & Histoplasma capsulatum, Coccidioides immitis & Chitin synthase inhibitors & [78] \\
\hline Rabbit defensins NP-1 & Rhizopus oryzae, Aspergillus fumigatus & Chitin sequestration and inhibition & [80] \\
\hline Fengycins \& Surfactins & Rhizopus sp.,Fusarium sp. & $\begin{array}{c}\text { Disrupt membrane cell wall and DNA synthesis; } \\
\text { Mitochondrial disruptions }\end{array}$ & [133] \\
\hline Cystatins & Aspergillus niger \& A.parasiticus & Inhibit cysteine protease & [135] \\
\hline
\end{tabular}

and ultimately cell death [42]. RTD-1(Rhesus Theta Defensin 1), member of the defensin family showed antifungal property by membrane permeabilization and accumulation of reactive oxygen species against multidrug resistant Candida auris [43].

A broad-spectrum AMP named Skin-PYY found on frog Phyllomedusa bicolor, has shown to be effective against Aspergillus niger and Aspergillus fumigatus in moderation and on Microsporum canis, Trichophyton rubrum, Candida albicans, Arthroderma simii with much higher potential. Moreover, they exhibited less toxicity to host mammalian RBCs and macrophages even at higher concentrations.

Iturin $\mathrm{A}$ is found to show antifungal effectiveness by pore formation, ROS accumulation and cell wall damage along with one key mechanism which involved activation of Mitogen-Activated Protein Kinase (MAPK) (Han et al., 2015) against Candida, Fusarium, Trichosporon and Aspergillus spp. (Lei et al., 2019) Synergistic effect 


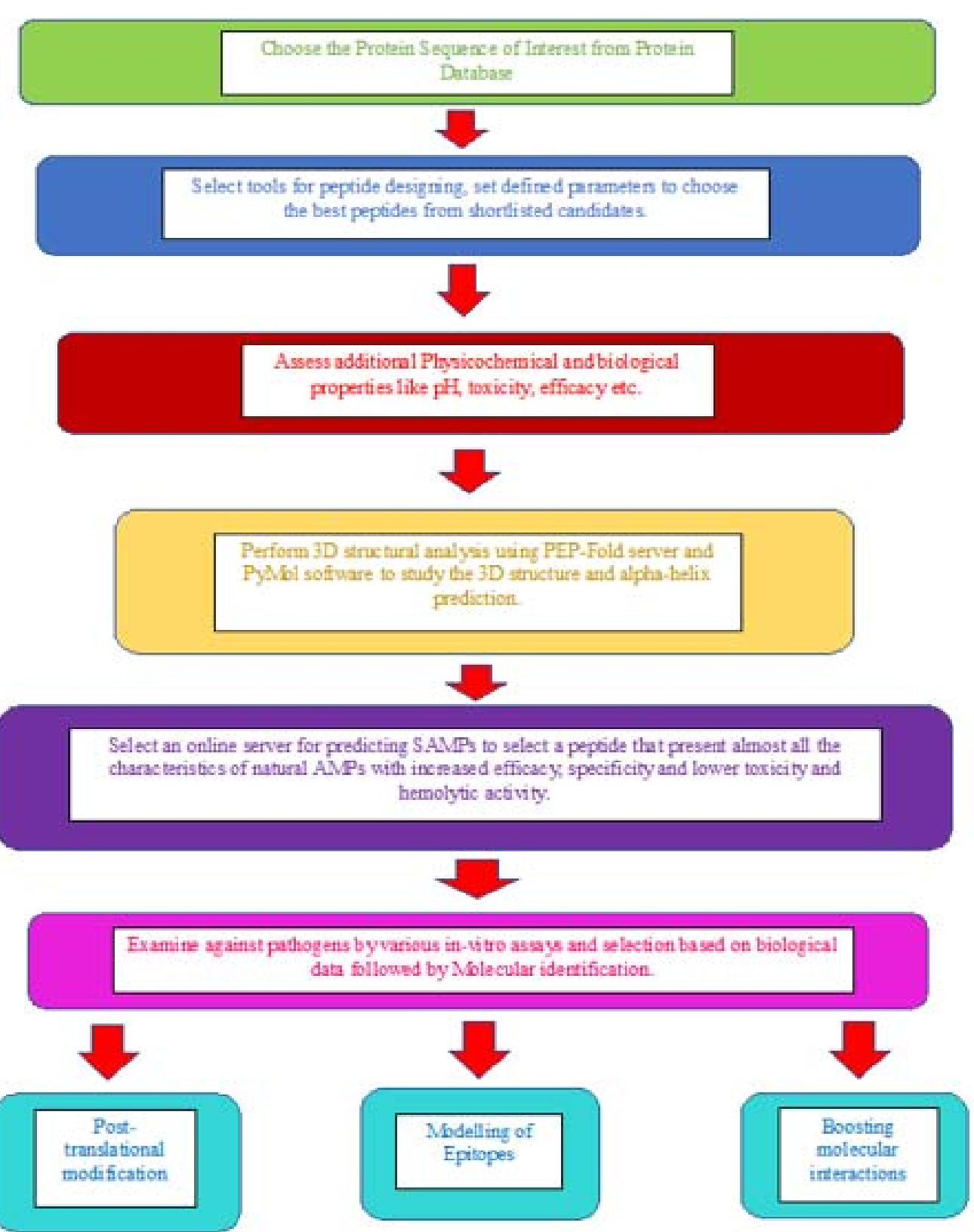

Figure 3: Pipeline to design Synthetic AMPs (SAMPs) based on any given protein sequence.

of Iturin A and Amphotericin B was also studied in C.albicans infected mice which showed better survival rates when both of them administered together into mice [48].

Zeamatin, an AMP extracted from seeds of Zea mays, showed antifungal activity by membrane layer permeabilization against C.albicans. Similar compounds were isolated from Triticum aestivum, Sorghum and Avena sativa but Zeamatin was found to be resistant to Mucorales, the resistant in Mucorales was attributed to lack of carbohydrate named beta-1, 3-glucan to which the AMPs bind on the membrane [49].

Aureobasidin A (AbA) is a cyclic non-ribosomal peptide produced a black mold amed Aureobasidium pullulans which showed effective antifungal activity against Histoplasma capsulatum, C. neoformans, Blastomyces dermatitidis and Candida species but Aspergillus spp. were resistant (Tan and Tay, 2013).

Cm-p1 is a hydrophilic, small peptide from snail Cenchritis muricatus [53] exhibits a broad spectrum activity against T.rubrum, F.oxysporum, A.niger, C.albicans. Low Hydrophobicity which was speculated to be the reason for low toxicity towards human erythrocytes [53]. A synthetic derivative of $\mathrm{Cm}-\mathrm{p} 1$, named $\mathrm{Cm}-\mathrm{p} 5$ was produced with increased static activity and minimal toxicity on mammalian cell lines against C.parapsilosis and C.albicans [54] , the modification was the increased affinity towards phosphatidylethanolamine and phosphatidylserine (membrane phospholipids in fungus) and reduced affinity of ergosterol [55]. 
Table 2: Detailed annotation present in APD, LAMP, CAMP, DAMPD, DRAMP are given below.

\begin{tabular}{|c|c|c|c|c|c|}
\hline Annotation & APD & CAMP & LAMP & DAMPD & DRAMP \\
\hline Name/Source & + & + & + & + & + \\
\hline Sequence/Length & + & + & + & + & + \\
\hline Physicochemical data & + & - & + & + & + \\
\hline Structure & + & + & + & + & + \\
\hline Antimicrobial activity & + & + & + & + & + \\
\hline Hemolytic activity & - & + & + & - & - \\
\hline Binding Target & + & - & - & - & + \\
\hline Cross-linking & - & - & + & - & - \\
\hline MIC with target organism & + & + & + & + & + \\
\hline Post-translational modification & + & - & - & - & - \\
\hline
\end{tabular}

\section{Cell wall targeting AMPs}

Glucan synthesis inhibitors: Fungal $\beta$-glucans are known as the most abundant form of polysaccharides present in the cell wall of pathogenic fungi and a source of Pathogen-Associated Molecular Pattern (PAMP) responsible for triggering immune responses in the host. It has a $\beta(1,3)$ backbone with protruding $\beta(1,6)$-linked branches conferring strength to the fungal pathogens [56]. Various fungal sources represent different structural diversity [57]. From various non-ribosomal antifungal peptides like echinocandins and pneumocandin which are secondary metabolites [58] from various fungal sources and act as non-competitive inhibitors of beta- $(1,3)$ glucan synthase, an essential enzyme responsible for generating fungal cell wall have been used to generate synthetic derivatives, namely, Echinocandin drugs which are being used as clinical antifungal drugs from last 20 years. Zalerion arboricola is responsible for the production of Pneumocandins which shows potent antifungal activity against Candida and Aspergillus spp.[59] whereas lipopeptide Echinocandin B isolated from Aspergillus nidulans shows potent antifungal activity against Candida spp.but they show high toxicity and hemolytic activity against mammalian cells simultaneously and inorder to reduce that semi-synthetic derivatives are optimized like cilofungin, anidulafungin, caspofungin, micafungin [60] etc, to address the limitations of natural AMPs like activity spectrum and toxicity (Hope et al., 2012).

Clinically approved echinocandins have certain drawbacks related to increasing drug resistance and intravenous delivery. These limitations have been addressed by next-generation echinocandins like SCY-078 which is both intravenous and orally administered betaglucan synthase inhibitor drug.

Chitin synthesis inhibitors: Chitin is also one of the major components of the Carbohydrate skeleton of the fungal cell wall and septa of all pathogenic fungi [65]. It is a $\beta(1,4)$-linked homo polymer of $\mathrm{N}$-acetylglucosamine, present in the cell walls of all fungi studied till date (Lenardon et al., 2010). The polysaccharide folds back on itself resulting in the formation of anti-parallel chains which give rise to intra chain hydrogen bonds formation strengthening the carbohydrate and converting them into very strong fibrous microfibrils, making it tougher than any other molecule in nature [65]. These microfibrils are further attached covalently to $\beta(1,3)$ glucan) making all the potent antifungals almost ineffective. Chitin plays a major role in cell viability and modulation of the host immune response and the amount of chitin present in the fungal cell walls also varies with different microbes, like Hyphae of C.albicans was observed to have 10 times more residues of $\mathrm{N}$-acetylglucosamine than cells of Saccharomyces cerevisiae, which is correlated with increased resistance to echinocandin drugs [68]. Inhibition of synthesis of chitin is a major target for antifungal therapies but chitin synthase inhibitor has ever reached the stage of clinical practice. The peculiar response of cell wall damage seen in fungus is the increased chitin production by class IV enzymes namely, ScChs3 and CaChs3, which in turn strengthens the fungal cell wall making them even more resistant to fungicidal attack. Nikkomycins and Polyoxins are potent inhibitors of Chitin synthase but are only effective against class 1 enzymes and show less potent activity against other classes of chitin synthases and in vivo fungal proliferation. For example, Nikkomycin Z, dipeptide synthesized by Streptomyces tendae competitively inhibit chitin synthases [69] and show potent activity against Coccidioides immitis and B.dermatitidis and moderate activity against Histoplasma capsulatum (Goldberg et al., 2000). It shows synergistic effects with echinocandin drugs to show potent activity against Aspergillus fumigatus (Ganesan et al., 2004) opportunistic pathogenic fungi named Alternaria infectoria, which in turn is moderate when used alone. It also synergizes with caspofungin and micafungin against C. albicans and C.parapsilosis biofilms (Kovács et al., 2019). Similarly, nucleoside-tripeptide antifungals, Polyoxins (A to L) are effective chitin inhibitors of phytopathogenic fungi like Botrytis and Alternaria [78] as well as human pathogens like Candida neoformans and Candida albicans [79].

Rabbit defensins (NP-1) shows potent activity against Rhizopus oryzae C.immitis, A.fumigatus (Levitz et al., 1986), C.neoformans. The mode of action is speculated to be Chitin sequestration [80].

Mannan binding peptides: Mannan is the outermost layer composed of heavily glycosylated proteins forming strong mannan fibrils containing alpha- and beta-linked oligo mannosyl residues [83] mainly involved in adhesion resulting in biofilm production and virulence and immune regulation (Lenardon et al., 2010).

Secondary metabolites like benanomicins produced by Actinoallomurus spadix and pradimicins produced by Actinomadura hibisca, show potential activity against fungal cell wall mannans against broad spectrum of fungal pathogens.

Pradimicin A also showed fungicidal effects against pulmonary and vaginal candidiasis, aspergillosis, trichophyton skin infection in mice with both intravenous and topical treatment [86]. These non-ribosomal peptides recognize D-mannose in the way similar to that for lectins in the presence of calcium (Nakagawa et al., 2019), ultimately cell death and ROS accumulation.

Nucleic acid inhibitors: There are various mechanisms by which AMPs attack the nucleic acids of fungal pathogens like targeting biosynthesis and metabolism by binding to DNA or its accessory proteins but a specific mechanism of action is not clear yet. Major nucleic acid inhibitors includes, Buforins which are isolated from toad's gut are known to originate from pepsin-directed histone $\mathrm{H} 2 \mathrm{~A}$ proteolysis [89] is a cryptic peptide which is known to show great antifungal activity against C. neoformans and C. albicans [90] 
Table 3: Various AMP specific databases which are used widely in the In-silico studies.

\begin{tabular}{|c|c|c|c|}
\hline Database & Link & Description & References \\
\hline AMPer & http://www.cnbi2.com/cgi-bin/amp.pl & Plant and Animal AMPs & [142] \\
\hline CAMP (Collection of AMP) & http://www.bicnirrh.res.in/antimicrobial & $\begin{array}{l}\text { Has a collection of } 6756 \text { AMPs and 3D structures of } \\
682 \mathrm{AMPs}\end{array}$ & [139] \\
\hline $\begin{array}{l}\text { LAMP (Linking AMPs } \\
\text { database) }\end{array}$ & www.biotechlab.fudan.edu.cn/database/lamp/index.php & $\begin{array}{c}\text { Has curated almost } 5547 \text { AMPs sequences of } 3,904 \\
\text { natural and } 1,643 \text { synthetic AMPs }\end{array}$ & [140] \\
\hline $\begin{array}{l}\text { YADMP (Yet another } \\
\text { database of AMPs) }\end{array}$ & http://yadamp.unisa.it & $\begin{array}{l}\text { Provides more information regarding QSAR analysis } \\
\text { and prediction of activity on target bacteria. }\end{array}$ & [147] \\
\hline APD(AMP database) & http://aps.unmc.edu/AP/main.php & $\begin{array}{l}\text { Natural AMPs from human, bacteria, fungi, plants etc. } \\
\text { and synthetic AMPs, } 403 \text { unique 3D crystal structures. }\end{array}$ & {$[148,149]$} \\
\hline RAPD & http://faculty.ist.unomaha.edu/chen/rapd & Recombinant AMPs & [150] \\
\hline BaAMPs & tttp://www.baamps.it & $\begin{array}{c}\text { Repository of } 221 \text { Biofilm active AMPs }+1022 \text { no. of } \\
\text { experimental data }\end{array}$ & [150] \\
\hline
\end{tabular}

by penetrating membranes without any pore formations and is speculated to have possible interactions with nucleic acids [89]. For example, buforin II is associated to have specific interaction with major groove, but the mechanism of action is unclear [89].

Actinomycin D synthesized by Streptomyces has clinical applications as antifungal agent and antineoplastic, it is known to intercalate DNA of fungal pathogens. Similarly, RSP 01, and RSP 02 (Rathod et al., 2018) show similar mechanisms and have structure similar to actinomycin D [91]. Another class of AMPs named Indolecithins isolated from bovine neutrophils are known to exhibit potent fungicidal activity against A.flavus, C.krusei, C.albicans and T.beigelii but only moderate effects on C.glabrata and P.carinii. There have been speculations that it works by affecting DNA processing enzymes and repair mechanisms (Marchand et al., 2006).

\section{Advantages of Natural AMPs}

AMPs have a wide array of advantages over conventional antibiotics/fungals. The major one is reducing the drug resistance as they interact with the bacterial membranes and fungal cell walls by neutralizing the charge and pore formation, and further penetrate through the microbial cells and causing cell death, reducing the possibility of drug resistance compared to conventional antibiotics/ fungals. They display broad-spectrum antibacterial, antifungal and antiviral activities (Mahlapuu et al., 2016a). They are also potent with rapid germ-killing ability and are required in low fungicidal and bactericidal concentrations, even effective on traditional antibioticresistant strains, and even have synergistic effects with typical antibiotics to neutralize endotoxin $[9,96]$.

These AMPs are safer options with little or no toxic side effects, and hard to induce drug resistance compared to the normal antibiotics. They also have good thermal stability and good water solubility (Dehsorkhi et al., 2014). They are effective molecules with lower production cost, simpler structure-activity relationships, and low sensitization (Raguse et al., 2002) and can be used clinically and in novel therapeutic drug design and development.

\section{Need for Synthetic/Semi-synthetic AMPs (SAMPs)}

The inception of rapid increase in drug resistant pathogens have augmented the worldwide research to find novel antimicrobial alternatives which can be produced in large numbers and in a short time scale giving enormous options to treat human diseases based on individual preferences and requirements. Wide research is going on characterizing such novel alternatives from their natural sources like animals, microorganisms, plants etc. but they require much time and effort. Compared to the speed with which antibiotic resistance is emerging, the speed of novel natural AMPs production is relatively low. To overcome such time lag, researchers have been suggesting to shift their focus on synthesizing synthetic and semi-synthetic AMPs, also abbreviated as SAMPs using protein engineering and systems biology approaches which can save much time and effort. Moreover, it also helps in overcoming other limitations of Natural AMPs which are known to hamper the potent antimicrobial action like low specificity and selectivity [101], manufacturing cost is relatively high [102], higher toxicity to host cells, and the robust guideline is not available for rational design [96], lack of stability against harsh environment, proteases and $\mathrm{pH}$ and they are also needed in higher concentration, reduced activity when used for surface coating [103], and bacterial resistance to some AMPs.

\section{Physicochemical Properties Taken into Account while Designing SAMPs}

Evident from the studies of synthetic and modified AMP studies, it is easy to change characteristics of an AMP with even very minute modifications [96]. Even the AMPs with almost similar structural organization can have exceptionally different modes of action and varied range of the targeted cells. Therefore, we need to understand the effects that structural modifications have on the physicochemical characteristics of AMPs as well as their target spectrum and activity. The AMP structure is certainly important, while the size, charge, hydrophobicity, amphipathicity and solubility are all crucial physiochemical properties for their antimicrobial activities and target specificity of AMPs, manoeuvering these changes can help us in modifying the target spectrum and activity of AMPs.

\section{Net charge}

Sum of all charges of ionizable groups present on the peptide chain. The range varies from -ve to +ve values. It's mainly responsible for the initial interaction of negatively charged membranes of a cell, which is the main target for many AMPs. There has been evidence that altering the net charge of AMPs can have an effect on antimicrobial and hemolytic activity. It also improves selectivity with almost no effect on the host cells. A study conducted by Jiang Z. et al. (2008) on $P$. aeruginosa demonstrated the effects of no. of +vely charged residues which varied from 1 to 10 and net charge of the hydrophilic face who's range varied from -5 to +10 of peptide $\mathrm{L}-\mathrm{V} 13 \mathrm{~K}$ on its biological \& biophysical properties. The results showed the importance of the no. of both the residues on hemolytic and antimicrobial activity in 
the mode of action of $\alpha$-helical AMPs. One of the most interesting findings was the sharp switch of hemolytic activity on increasing one positive charge on the polar face resulted in a greater than 32 -fold increase in hemolytic activity [104].

\section{Length}

Length of AMPs is taken into thought when designing synthetic/ semi-synthetic AMPs. A study conducted by Liu Z. et al.,(2020) demonstrated the effect of length of antimicrobial/antifungal peptides of the (RW)n series which are known to interact with bilayers containing the headgroup phosphatidylglycerol which is negatively charged relative to the ones having a zwitterionic headgroup, phosphatidylcholine. In which they demonstrated the length effects of the chain on the anti-pathagocytic activity, in which formation of a peptides series was observed having simple sequence repeats, (RW) $\mathrm{n}-\mathrm{NH} 2$ ( $\mathrm{n}=1,2,3$, and so on), and were evaluated on the grounds of their antimicrobial and hemolytic activity. The antimicrobial activity of the peptides was found to increase with chain length, as does the hemolytic activity in case of RBCs. The peptides with higher chain length showed almost similar values for the hemolytic index. The (RW) 3 indicates the desirable value chain length in terms of synthesis efficacy and selectivity measured by the hemolytic index. Minimum 7-8 amino acids are required to form amphipathic structures with polar and nonpolar groups on the opposite sides of a peptide molecule [96]. Similarly, a shorter derivative of HP (2-20) analog peptide exhibited 300 times less toxicity and enhanced antimicrobial activity by deleting the $\mathrm{N}$-terminal random coil region [105].

\section{Helicity}

Helicity of an AMP is defined as its ability to form spin structure. Various AMPs produced in humans have shown to exhibit antifungal properties but because of low selectivity and activity they remain inefficient. A study was conducted on a-peptide AMPs against commensal Candida albicans have revealed that hydrophobicity and helicity, governed the activity and selectivity of 14 -helical $\beta$-peptides against $C$. albicans and human erythrocytes, more stable helical conformations prompted specificity for C. albicans over a wide scale of hydrophobicity (106). Various studies have demonstrated that helicity is a more important factor to be considered for toxicity compared to antimicrobial action. A study demonstrated that adding D-amino acids into the primary peptide sequence had shown significant reduction in the hemolytic activity of AMPs while the antimicrobial effect remained unchanged. Thus, helicity can be diminished by fusing $\mathrm{D}$-amino acids into the primary sequence. It was observed by Papo et al. (2002) that by replacing $35 \%$ of the 1 -amino acids with d-amino acids almost eliminated the hemolytic activity [107]. Moreover, they were observed to be resistant to protease degradation, making them more stable than before. Another major factor to be considered was Helix propensity of each amino acid in the peptide sequence, an average globular protein usually contains $30 \%$ alpha-helix, which is the most common type of secondary structure. Some amino acids occur more frequently in alpha-helices than others; this tendency is known as helix propensity [108]. For example, while designing alphahelical residues, proline and glycine are not given much preference because of low helix propensities [108].

\section{Hydrophobicity}

Has major influence on the activity and selectivity of AMPs. If hydrophobicity is increased at the positive side of primary peptide sequences can significantly increase the antimicrobial property of AMPs [109]. For every AMP molecule there is an optimum value of hydrophobicity, after which sudden decrease in the activity is observed [110]. Therefore, an optimal value of hydrophobicity has to be considered while designing synthetic AMPs and increasing hydrophobicity at the non-polar face can facilitate an increase in the antimicrobial activit. Studies have also revealed that if the hydrophobicity of the peptide is expanded vigorously it can positively alter the range of targets for which it is used (Zelezetsky et al., 2005).

\section{Amphiphilicity}

High levels of amphiphilicity are considered as one of the major emblems of the interfacial helices in the membrane-active peptides like AMPs which has a key role in membrane-interface binding. A helix which is amphiphilic in nature is regarded as one of the major structural motifs in proteins (Huang et al., 2010). Studies have evaluated that amphipathicity is a major factor which impacts antimicrobial action than hydrophobicity [109] and is therefore, considered prior to hydrophobicity while designing synthetic AMPs. Some studies demonstrated that membrane lytic peptides group around in zones of high hydrophobicity (Khara et al., 2017) while others suggest that optimal amphiphilicity results in increased antimicrobial activity and cytotoxicity [116]. Whereas, a recent study conducted by Wang et al. (2018) showed that the toxicity of the engineered peptides was independent of the type of amphipathicity, which was greatly opposite of the previous studies [117].

\section{Natural Amps against Myceliated Fungi Which can be Targeted to Produce Synthetic Amps against Mucorales}

Mycelium is the vegetative part of fungus present in all myceliated fungi including Mucorales the largest order of Zygomycetes. Studying various antifungal peptides which show antifungal activity against myceliated fungi can aid in the development synthetic alternatives in a better way, studying their mechanism of action, structural and functional analysis, target specifity, stability can help in developing highly effective SAMPs.

\section{In-Silico Approach to Develop Synthetic Amps (Samps)}

Considering the advantages of in-silico development like easier commercial development, less production costs, time saving and overcoming the shortcomings of natural AMPs, they have been considered as an alternative and reliable option, where the molecular, biological and physiological environment in which AMPs work is simulated/imitated using computer programs and software. It is also considered as a logical annex to in-vitro biological studies carried out in the lab [136] to help in predicting, designing and modifying AMP in which one can perform variety of in-silico experiments using the virtually unlimited parameters from which one gets ample predictions of the applicable results.

APD involves re-arranging of amino acid sequences to generate either synthetic AFPs which are exclusively novel peptides involving the design of sequence and $3 \mathrm{D}$ structure or the semi-synthetic versions that fit the existing structural template involving the design of a sequence alone. 
The most common trend for rational drug designing is the use of either the pre-existing protein undergoing local modification or the fitting of an amino acid sequence on a given fold of protein [137]

Templates use combat the difficulty of predicting the folds of unknown sequences. Since the fold remains unaltered and the backbone atoms are placed on the framework directly. The side chains are then added to the backbone to create a stabilized and functional protein.

\section{Methods}

Dataset creation: Various bioinformatics tools are available these days for in-silico designing and screening of novel antifungal peptides using these molecular tools providing a wide array of proteomics and genomic data [138]. Dataset creation is considered as one of the most delicate parts of a generative model construction. These datasets are created using various lists of peptides based on their structural and functional classification from the online databases and servers specifically designed for extracting antifungal and other antimicrobial peptides along with additional information related to its target, structural and functional complexities, antimicrobial activity, cytotoxicity, hemolytic activity etc. These databases also have hyperlinks to various external prediction tools and related databases like NCBI, UniProt, ProSite, SwissProt, etc. [139-141]. These methods have been used to as much information possible from the iterative scanning of scientific literature and public sources available in order to fasten the process of peptide design [142].

Some commonly found databases are of 2 types: Common Databases and Specific Databases.

Common databases: Common databases mainly include different kinds of AMPs, it does not include the sources and types of different kinds of AMPs. The Collection of Antimicrobial Peptides (CAMP) includes an experimentally valid dataset collection with sequences that are also deduced experimentally and is responsible for compilation of a patent dataset with patented antimicrobial sequences and predicted dataset with putative AMP sequences based on similarity [143]. The updated version of CAMP, it has sequences, structures and familyspecific signatures of Prokaryotic and Eukaryotic AMPs. A database Linking Antimicrobial Peptides (LAMP) has its AMPs divided into into same three datasets as CAMP but it has both Natural and Synthetic AMPs as well. The Antimicrobial Peptide Database (APD) collects peptides with guaranteed curation, its earlier versions only contained mature sequences with less than 100 amino acid residues but the newer version it contains AMPs with 200 amino acids, newly annotated AMPs with antibiofilm, antibacterial, antifungal, insecticidal properties etc and a few general synthetic AMPs are also present in the list [144]. The Dragon Antimicrobial Peptide database (DAMPD) contains a mix of precursor and mature AMP sequences. The Data Repository of Antimicrobial Peptides (DRAMP) have a detailed annotation in the form of Antimicrobial activity and structural data [145].

Peptides in these common/general databases are well annotated on the basis of structure, activity, physicochemical and reference information etc. If we compare the peptides from different databases, 2452 in APD, 4475 in CAMP, 16876 in DRAMP, 5546 in LAMP respectively which are compared on sequence level. The complete set constitutes 19062 sequences out of which 1408 are identical in all 4 databases. 36 sequences were identical in both APD and DRAMP, 53 in both APD and LAMP, 123 in APD and CAMP, 901 in LAMP and DRAMP, 201 in LAMP and CAMP, 99 in CAMP and DRAMP respectively.

In APD and DRAMP, the binding targets are annotated in APD and DRAMP. Whereas, LAMP additionally provide a cross linking annotation to offer to provide hyperlinks to other databases [146].

Besides storage and search function these general databases have integrated various tools for comparison, prediction and peptide design like BLAST for sequence homology searches, ClustalW for sequence alignment, Prediction tools are developed for AMP identification, physico-chemical properties and secondary structure prediction.

Specific databases: To cater the need to accommodate more extensive subclasses of AMPs, various databases were established focusing on specific types, sources and characteristics of AMPs. Egs: AMPs can be divided based on biological activity as antifungal, antibacterial, plant AMPs etc. Division is also done on the basis of molecular properties, covalent bonding, molecular targets, 3D-patterns etc.

Some examples of such databases are Defensins knowledgebase which primarily focus on defensins family which are small cysteinerich cationic peptides, stabilized by 3-4 conserved cysteine disulfide bridges. Thiobase mainly includes thiopeptides, produced by gram positive bacteria. They show potency for various gram-positive bacterial and fungal strains, including the drug resistant pathogens. Peptaibols database consists of an unusual class of peptides known as Peptaibols which are a non-ribosomally encoded peptides from soil fungi exhibiting antibacterial and antifungal properties. Hemolytik database has a repository corresponding to hemolytic activities of peptides, considering it as one of the limitations in constructing therapeutic AMPs because of the toxicity to peptides, such database resources are considered valuable to researchers as they include the information pertaining to the source of erythrocytes used and the measured hemolytic activity [146].

Template based methods: Template based approaches mainly involve searching for an appropriate template followed by modification of the interface of the template to improve the binding affinity with its specific target to design AFPs with greater antifungal activity and reduced toxicity [151]. Natural AFPs are used as templates like cecropins, magainins, protegrins etc to identify the positions that are important for the activity of these AFPs. In the majority of studies conducted, in which these AFPs have been used to design various synthetic AFPs, the physico-chemical properties like charge and amphiphilicity were taken into account to analyse the peptide activity of the synthetic alternatives $[109,152,153]$. These studies have proved the importance of specific amino acids and their residue positions on the activity of these peptides. However, there are certain limitations associated with this local approach like its inability to shed light on the interactions between amino acids that influence the global three-dimensional conformation of the peptide. The model used for template based studies on the natural antifungal peptide was the linguistic model in which sequences were treated as "text" 
and "formal grammar rules" formed by amino acid letters having individual properties like charge, amphiphilicity, hydrophobicity values etc. to identify various text patterns. The synthetic novel alternatives constructed through this model were found to be better than the natural analogues which apparently suggested the use of this model to find out the functionally relevant patterns and motifs in a peptide sequence [154].

Various peptides were also produced de novo containing lysine, leucine and tryptophan residues. The length of the amino acid sequence and tryptophan residues were analyzed for its corresponding anti-microbial activity. Various peptide sequences capable of forming amphipathic helices were also designed using valine and arginine amino acid residues.

Cationic amphiphilic peptides also designed using this approach were shown to have membrane lytic effects against C.albicans [152] Using this approach it was found that peptides having higher hydrophobic residues showed higher hemolytic effect on RBCs compared to ones with lesser residues. The residues which lead to increased specificity and selectivity were also introduced like the ones which were positively charged in the center of non-polar face of amphipathic alpha-helical peptides were known to enhance peptide's selectivity along with reduced hemolytic activity and improved therapeutic potential [155].

Bio-physical studies: These studies mainly involve understanding AMP activity and designing improved variants by examining their structures in hydrophobic environments or by modelling peptides at the atomic level. It comprises of molecular modelling based on free energy perturbations which are based on statistical dynamics involving the calculation of free energy differences by break them into several smaller steps for a large receptor-ligand complexes, molecular dynamics simulations that are used to compute conformations and physical movements of molecules over a simulated period of time, various physically motivated forces fields in different surroundings are used to compute interaction energies between parties, along with thermodynamic calculations [8]. Using this approach, the hydrogen-bonding sites were also figured out [156,157]. However, these simulations are limited to peptides which interact with micelles and the initial conditions for simulations must be well defined, the time for practical simulation must be too short for spontaneous pore formation to be observed. Simulation based studies have been interpreted by a disordered toroidal pore model [158], only a few peptides are oriented in perpendicular fashion causing substantial membrane perturbations, and they do not cluster. These molecular dynamic simulations were used to develop the synthetic analogues of indolicidin and ovispirin $[159,160]$ in which the antifungal activity was enhanced two folds and hemolytic activity was increased ten folds.

\section{Virtual screening assays:}

QSAR \& molecular descriptors: Useful when synthesis of peptides is tedious, exhaustive and expensive. Moreover, techniques like the Phage display cannot be applied (Pande et al., 2010). These techniques have an advantage of a few priori assumptions, which are known to impute structures of the proteins based on primary sequences in which numerical methods are used to determine quantifiable properties of peptides such as hydrophobicity, charge etc. to relate such properties to biological activities of the peptides using SAR models, or more specifically QSAR(Quantitative Structure Activity Relationships) in which descriptors are used as input variables and biological activity as output variables $[163,164]$. These QSAR models for peptides are used as a guide for activity prediction and sequence optimization for variety of biological activities. Such computer assisted models lead to accurate estimation or prediction and sequence optimization of desired activity.

\section{Predictive tools:}

Parameter space strategy: A prediction interface developed by Antimicrobial Peptide Database based on the concept of Parameter space defined by its whole peptide set which is a set of threshold values calculated from natural AMPs in terms of hydrophobic percentage, length, net charge amino acid composition, etc. If we take net charge as an example, the already known AMPs in APD occupy a range from -12 to +30 which forms a boundary condition which is used in prediction detection program. While the majority of AMPs have a net charge between -5 and +10 , the core region which is taken as an alternative condition for prediction of AMPs. Similar concept is applied with hydrophobic content, length and other parameters constituting the parameter space. This prediction using APD is done in 3 steps: First of all, the parameters of an uploaded sequence are calculated and compared with the specific parameter spaces, followed by subdivision into AMPs and Non-AMPs. The AMP group is further sub-divided into three different classes namely as amino acids rich peptides, disulfide linked peptides and linear peptides. Final step involves sequence alignments to find 5 very highly homologous peptides existing in the APD [146].

Alignment methods: Alignment methods have foremost applications in pattern recognition of the sequences of DNA and proteins [165]. Developed a predictor tool for identification of AMPs using Blastp and feature selection methods. But there are certain limitations associated with this method, one is that AMPs have low homology in their sequences and fall into only small number of secondary structure classifications making it difficult to find patterns over sequence alignment algorithm making machine learning methods as one of the most relevant method to develop predictive models for AMP classification.

Artificial intelligence/Machine learning methods: Volumes of data is being generated annually in Bioinformatics research and because of rapidly growing machine-to-machine connections which posed an increased demand of optimizable data analytics tools. However, only small part of it is useful called the "Metadata or Target-rich data" which is incorporated into testable models to obtain predictory information using intersections of computer science and statistics namely Artificial Intelligence (AI) or Machine Learning (ML).

Artificial intelligence consists of huge set of data analytic tools and datasets for making computers behave rationally and intelligibly to solve complex problems mimicking the problem-solving and decision-making skills of a human mind.

AI comprises of various subsets like Machine Learning, Deep learning, Hidden Markov models, neural networks etc., composed of AI algorithms and has many applications overlapping with several 
other fields [166].

Machine learning is defined as the statistical representation of a real-world problem based on volumes of data generated to optimize and train a predictive model using AI algorithms from using example data or past experience. Increase in the use of AI/ML methods have advanced the field of drug discovery and drug design. In drug discovery, the ML models are trained using two datasets, a positive dataset collected from APD, CAMP, LAMP and other AMP related databases and a negative dataset which consists of randomly selected non-secretory protein sequences from UniProt databases, which aren't annotated for antimicrobial activity. Machine learning methods which are based On Support Vector Machines (SVMs), Random Forests (RF), Neural Networks (NNs) etc., are commonly used. In CAMP, 64 best peptide descriptors are used which are mainly structure, function, physico-chemical properties etc. [146]

Machine learning models are divided into 2 main types: Supervised and Unsupervised learning models. SVM is a type of supervised machine learning model which classify the data points by maximizing the margin between different classes in high dimensional space whereas, RF is a non-parametric tree-based approach that, combines the idea of adaptive nearest neighbors for effective data adaptive inference. $\mathrm{NN}$ involves an information-processing algorithms in a way the nervous system processes information composing vast number of highly connected processing elements names neurons or nodes to solve complex scientific problems. Machine learning methods are applied to assess the antimicrobial potential of new formed peptides.

Considering the derivation of natural AMPs from largely derived coded sequences from various genes. Therefore, machine learning models are employed to predict AMPs from unannotated genomic \& protein sequences. ML models have also been used for identification of antimicrobial activity of peptides, example is iAMP-2L a two-level classifier with an improved fuzzy K-nearest neighbor algorithm. The first layer differentiates an AMP from Non-AMP followed by the next layer which predicts the functional types as antibacterial, antifungal, antiviral, etc. [167].

It is a common computer-based approach which comprises a combination of sophisticated activity estimation along with stochastic optimizations involving random iterative patterns or processes. Various evolutionary and genetic algorithms are employed in-silico through successive generations of mutations like deletion, duplication, sequence shuffling etc., to design peptides with improved biological activity. However, these evolutionary algorithms are subject to certain limitations like dependency on parameter initialization, premature convergence and partially insufficient sampling etc. and have proven applications in various studies attributing to their overall robustness to experimental noise. [168-170].

The de novo drug designing is facilitated by two types of generation models used in machine learning namely Variational Autoencoders (VAEs) and Generative Adversarial Networks (GANs). In VAEs multiple molecular properties are imposed on a latent space in which these molecules are expressed as real vectors [171], it takes the input data which is the basis of continuous latent space. The addition of two known AMPs helps in generating novel alternatives which represent a progression between the two already known peptides [172]. While in
GANs, the input peptides are subjected to distribution and sampling to form a new set of novel peptides using predominantly two machine learning networks namely, generator and discriminator. Generator is responsible for formation of these new peptides and discriminator is used to differentiate between the real and counterfeit peptides [172].

Hidden markov models: HMM is a statistical, probabilistic graphical process which uses the Markov process containing hidden or the unknown parameters which are identified by the known or observed parameters set to find them. These hidden parameters when once found are used for further analysis. The Markov chain is identified by observing the vector series. The observed events have no correspondence but are linked through the probability distribution. It's a double stochastic process which describe state transitions and statistical relation between the states/hidden values and observed values [173]. One such application of HMM is AMPer, a database and an automated discovery tool for identifying antimicrobial peptides in which HMM models were constructed. 146 models were for mature and 40 for pro-peptides for individual AMP classes were created by clustering and analysis of various AMP sequence classes available in the literature and other public resources along with AMPs obtained by iterative scanning process of Swiss-Prot database. Minimum thresholds in the range of $10-90$ percent similarity were used to evaluate the resulting clusters followed by HMM profiles [174]. The HMMER software package (Eddy, 1998; http://hmmer.wustl.edu/) has been utilized to create one profile HMM for each AMP cluster. Clustal $\mathrm{W}$ was used to generate the multiple alignments used by HMMER. The HMMER package was chosen over other tools, because it is considered to be less sensitive to small misalignments in the multiple sequence alignments and to report reliable E-values [175]

Basic steps involved in the production and designing of synthetic and semi-synthetic alternatives of AMP involves a step by step approach which utilizes various bioinformatics tools and databases for the extraction of viable peptides from the entire genome, from these extracted peptides, a few potent candidates are selected which are examined against pathogen and selection based on biological action is done followed by molecular identification which involves modeling of epitopes, modification in post-translational organization and boosting interaction between molecules (176).

\section{Workflow pipeline for bioinformatics and structural analysis}

The workflow pipeline for designing SAMPS involves Bioinformatics analysis in which prediction and characterization of Antimicrobial peptide is performed to design SAMPs in which random protein sequences are chosen from NCBI database (https://www.ncbi. nlm.nih.gov/) followed by analysis using various online server like CellPPD (http://crdd.osdd.net/raghava/cellppd/submission.php), which is used to design cell penetrating peptides [177] and dPABBs (http://ab-openlab.csir.res.in/abp/antibiofilm/protein.php), which is used to design peptides with antibiofilm activity [178].

Peptides with favorable characteristics are chosen and are then assessed based on the physicochemical properties, we have mentioned above in this article. Various online bioinformatics servers are used to calculate hydrophobic ratio, helix propensity, Boman index, net positive charge [179] like Antimicrobial peptide database tool [180], Molecular mass, pI, cleavage sites, proteolysis resistance can be 
assessed using APDB tool, ProtParam, Peptidecutter, HLP servers respectively (Sharma et al., 2014; Wang et al., 2016). After the assessment the peptides are blasted against the anticrobial database APDB with experimentally tested antimicrobial peptides of fungal and bacterial origin [148].

Various additional biological properties like antimicrobial potential, hemolytic and toxicity value allergic potential is calculated using iAMPpred tool [183], HemoPI tool [184], ToxinPred tool [185] and Antigenic.pI tool [186] respectively to increase the chances to have antimicrobial peptide.

After the prediction and characterization is over, it is followed by the Structural analysis in which 3D structure and alpha-helix prediction of peptides are being evaluated by simulations in which an online server name PEP-FOLD [187] is used in which candidate peptides are anticipated on the basis of lower sOPEP energy and High Tm values [187]. Further analysis is done using PyMol Molecular Graphics System. Helicity is also regarded as an important factor to be considered while designing AMPs and is therefore, calculated using Rampage [188] which involves Ramachandran plotting, hydrophobicity moment and wheel projection is predicted using HeliQuest [176]. The candidate antimicrobial peptide selected are then synthesized commercially which are then subjected to invitro biological assays to evaluate their antifungal, antibacterial, antiviral potential.

Several other Bioinformatics tools are also used like AMPer asset which is used to classify naturally occurring AMPs and predict new AMPs using Hidden Markov Models (HMM) (Fjell et al., 2008).

Various computational and statistical algorithms like Support Vector Machines (SVM), Hidden Markov Models (HMM), artificial neural networks, Fuzzy k-nearest neighbor approach, Chemiinformatics approaches have led to development and recognition of these novel alternatives (190). There are 3 specific approaches used for developing and designing sythetic and semi-synthetic AMPs are namely Virtual screening study, Template based study, Biophysical studies [8]. Which help us in saving much time and resources [136].

\section{Conclusion and Future Prospects}

Antimicrobial peptides research is considered as one of the global research buffer zones, but the limitations associated with its design and applicability need to be addressed immediately. Indeed, the AFPs show promising antifungal activity but their toxicity, hemolytic activity to normal cells is one of the major issues that needs to be addressed in the terms of applying them to broad clinical uses. The intersection of multi-disciplinary approaches like Biotechnology, Biochemistry, Omics, Bioinformatics, Pharmacology can be used to develop potential AFPs curbing the limitations of natural AFPs and their use. Proteomics involving the large-scale study of proteins which are the vital parts of living organisms requiring computational \& statistical applications Hidden Markov Models, Artificial Intelligence or Machine learning models like Support Vector Machines can be used to construct prospective AFPs. Molecular dynamics simulations-based methods can be used to study the mechanism of action of AFPs to understand to construct better AFPs instead of just relying one sided experimental research, Peptidomimetics is one such promising area of research which involves synthesis of peptide derivatives that mimic the physicochemical properties and biological properties discussed previously in this article. Nevertheless, they exhibit resistance to protease degradation, longer half-life and much higher bioavailability and several procedures are going on to design improved AFPs with alternative backbones. Peptidomimetics like peptoids, AApeptides, staple peptides etc., have shown lower toxicity on normal cells compared to existing natural peptides. Various studies have also shown that use of AFPs encounter 2 setbacks, one is development of resistance, not only antifungal agents but AFPs have also shown the development of their resistance in the human body. Moreover, we require them in comparatively higher concentration and higher concentration subject to toxicity. To counter these two setbacks if we encourage the development of peptidomimetics using in-silico approaches like template design, molecular dynamics, AI/ ML etc., and devise combinatorial drug therapies including the collation of Antifungals along with AFPs can be used as an effective approach to counter these two setbacks concerning resistance and toxicity development. Thus, using In-silico approaches one can study the development of such synthetic analogues which show synergism with the current antifungals agents used in the therapy and carefully. In-silico approaches are a promising alternative to chemical synthesis and use of genetically engineered bacteria to which are currently one of the mainstream procedures reduce the cost of chemical substrates, equipment, capital, resources, time and energy. Further research is needed to develop better multi-view computational algorithms with optimization for interactive and iterative processing to study the alternatives for combinatorial therapy and their structure- function relationships to slump the limitations and progress against the current low success rates of AMPs/AFPs in clinical settings.

\section{References}

1. Chakrabarti A, Chatterjee SS, Das A, Panda N, Shivaprakash MR, Kaur A et al. Invasive zygomycosis in India: Experience in a tertiary care hospital. 2009; 85: 573-581.

2. Ribes JA, Vanover-Sams CL, Baker DJ. Zygomycetes in Human Disease. Clin Microbiol Rev. 2000; 13: 236-301.

3. Al-Hatmi AM, Hagen F, Menken SB, Meis JF, Hoog GS De. Global molecular epidemiology and genetic diversity of Fusarium, a significant emerging group of human opportunists from 1958 to 2015. Emerging Microbes and Infections. Nature Publishing Group. 2016; 5: 124

4. Fisher MC, Hawkins NJ, Sanglard D, Gurr SJ. Worldwide emergence of resistance to antifungal drugs challenges human health and food security. Science. American Association for the Advancement of Science. 2018; 360: 739-742.

5. Cesare GB De, Cristy SA, Garsin DA, Lorenz MC. Antimicrobial peptides: A new frontier in antifungal therapy. MBio. 2020; 11: 1-21.

6. Caramalho R, Tyndall JDA, Monk BC, Larentis T, Lass-Flörl C, Lackner M. Intrinsic short-Tailed azole resistance in mucormycetes is due to an evolutionary conserved aminoacid substitution of the lanosterol 14a-demethylase. Sci Rep. 2017; 7: 15898.

7. de Ullivarri MF, Arbulu S, Garcia-Gutierrez E, Cotter PD. Antifungal Peptides as Therapeutic Agents. Frontiers in Cellular and Infection Microbiology. Frontiers Media S.A. 2020; 10: 105

8. Fjell CD, Hiss JA, Hancock REW, Schneider G. Designing antimicrobial peptides: Form follows function. Nature Reviews Drug Discovery. Nature Publishing Group. 2012; 11: 37-51.

9. Mahlapuu M, Håkansson J, Ringstad L, Björn C. Antimicrobial peptides: An emerging category of therapeutic agents. Frontiers in Cellular and Infection Microbiology. Frontiers Media S.A. 2016; 6. 
10. Fox JL. Antimicrobial peptides stage a comeback. Nat Biotechnol. 2013; 31 : 379-382.

11. Czaplewski L, Bax R, Clokie M, Dawson M, Fairhead H, Fischetti VA, et al. Alternatives to antibioticsâ€"a pipeline portfolio review. Elsevier. 2016; 16 239-251.

12. Mahlapuu M, Håkansson J, Ringstad L, Björn C. Antimicrobial peptides: An emerging category of therapeutic agents. Frontiers in Cellular and Infection Microbiology. Frontiers Media S.A. 2016; 6: 194.

13. Lai $Y$, Gallo RL. AMPed up immunity: how antimicrobial peptides have multiple roles in immune defense. Trends in Immunology. 2009; 30: 131 141.

14. Hancock REW, Diamond G. The role of cationic antimicrobial peptides in innate host defences. Trends in Microbiology. 2000; 8: 402-410.

15. Nguyen LT, Haney EF, Vogel HJ. The expanding scope of antimicrobial peptide structures and their modes of action. Trends in Biotechnology. Trends Biotechnol. 2011; 29: 464-472.

16. Yamamoto $T$, Umegawa $\mathrm{Y}$, Yamagami $\mathrm{M}$, Suzuki $\mathrm{T}$, Tsuchikawa $\mathrm{H}$ Hanashima S, et al. The Perpendicular Orientation of Amphotericin B Methyl Ester in Hydrated Lipid Bilayers Supports the Barrel-Stave Model. Biochemistry. 2019; 58: 2282-2291.

17. Anderson TM, Clay MC, Cioffi AG, Diaz KA, Hisao GS, Tuttle MD, et al Amphotericin forms an extramembranous and fungicidal sterol sponge. Nat Chem Biol. 2014; 10: 400-406.

18. Gray KC, Palacios DS, Dailey I, Endo MM, Uno BE, Wilcock BC, et al Amphotericin primarily kills yeast by simply binding ergosterol. Proc Natl Acad Sci U S A. 2012; 109: 2234-2239.

19. Mesa-Arango AC, Trevijano-Contador N, Román E, Sánchez-Fresneda R, Casas C, Herrero E, et al. The production of reactive oxygen species is a universal action mechanism of amphotericin $B$ against pathogenic yeasts and contributes to the fungicidal effect of this drug. Antimicrob Agents Chemother. 2014; 58: 6627-6638.

20. Bolintineanu DS, Kaznessis YN. Computational studies of protegrin antimicrobial peptides: A review. Peptides. 2011; 32: 188-201.

21. Pouny $Y$, Rapaport D, Shai $Y$, Mor A, Nicolas $P$. Interaction of Antimicrobial Dermaseptin and its Fluorescently Labeled Analogs with Phospholipid Membranes. Biochemistry. 1992; 31: 12416-12423.

22. Bechinger $B$. Detergent-like properties of magainin antibiotic peptides: $A^{31} P$ solid-state NMR spectroscopy study. Elsevier.2005; 1727: 101-108.

23. Bergaoui I, Zairi A, Tangy F, Aouni M, Selmi B, Hani K. In vitro antiviral activity of dermaseptin S4 and derivatives from amphibian skin against herpes simplex virus type 2. J Med Virol. 2013; 85: 272-281.

24. Mor $A$, Nicolas $P$. Isolation and structure of novel defensive peptides from frog skin. Eur J Biochem. 1994; 219: 145-154.

25. Dong JY, Lee G. Research Communication Cecropin A-induced Apoptosis is regulated by Ion Balance and Glutathione Antioxidant System in Candida albicans. Wiley Online Libr. 2016; 652-662.

26. Turner J, Cho Y, Dinh NN, Waring AJ, Lehrer RI. Activities of LL-37, a cathelin-associated antimicrobial peptide of human neutrophils. Antimicrob Agents Chemother. 1998; 42: 2206-2214

27. Fan D, Coughlin LA, Neubauer MM, Kim J, Kim MS, Zhan X, et al. Activation of HIF-1 $\alpha$ and LL-37 by commensal bacteria inhibits Candida albicans colonization. Nature Medicine. Nature Publishing Group. 2015; 21: 808-814.

28. Tsai PW, Yang CY, Chang HT, Lan CY. Human antimicrobial peptide LL 37 inhibits adhesion of Candida albicans by interacting with yeast cell-wall carbohydrates. PLoS One. 2011; 6: 17755.

29. Hancock RE. Cationic peptides: Effectors in innate immunity and nove antimicrobials. Lancet Infectious Diseases. Lancet Infect Dis. 2001; 1: 156164.

30. Lipkin R, Pino-Angeles A, Lazaridis T. Transmembrane Pore Structures of $\beta$-Hairpin Antimicrobial Peptides by All-Atom Simulations. J Phys Chem B.
2017; 121: 9126-9140.

31. Benincasa M, Scocchi M, Pacor S, Tossi A, Nobili D, Basaglia G, et al. Fungicidal activity of five cathelicidin peptides against clinically isolated yeasts. J Antimicrob Chemother. 2006; 58: 950-959.

32. Park J, Kwon O, An HJ, Park KK. Antifungal effects of bee venom components on trichophyton rubrum: A novel approach of bee venom study for possible emerging antifungal agent. Ann Dermatol. 2018; 30: 202-210.

33. Khan RS, Iqbal A, Malak R, Shehryar K, Attia S, Ahmed T, et al. Plant defensins: types, mechanism of action and prospects of genetic engineering for enhanced disease resistance in plants. 3 Biotech. Springer Verlag. 2019, 9: 192.

34. Games PD, dos Santos IS, Mello ÉO, Diz MSS, Carvalho AO, de SouzaFilho GA, et al. Isolation, characterization and cloning of a cDNA encoding a new antifungal defensin from Phaseolus vulgaris L. seeds. Peptides. 2008; 29: $2090-2100$.

35. Mello EO, Ribeiro SFF, Carvalho AO, Santos IS, Cunha M Da, SantaCatarina $\mathrm{C}$, et al. Antifungal activity of PvD1 defensin involves plasma membrane permeabilization, inhibition of medium acidification, and induction of ROS in fungi cells. Curr Microbiol. 2011; 62: 1209-1217.

36. Thevissen K, Terras FRG, Broekaert WF. Permeabilization of fungal membranes by plant defensins inhibits fungal growth. Appl Environ Microbiol. 1999; 65: 5451-5458.

37. Koo JC, Lee SY, Chun HJ, Cheong YH, Choi JS, Kawabata SI, et al. Two hevein homologs isolated from the seed of Pharbitis nil L. exhibit potent antifungal activity. Biochim Biophys Acta - Protein Struct Mol Enzymol. 1998 1382: 80-90.

38. Park SC, Lee JR, Kim JY, Hwang I, Nah JW, Cheong H, et al. Pr-1, a novel antifungal protein from pumpkin rinds. Biotechnol Lett. 2010; 32: 125-130.

39. Taveira GB, Carvalho AO, Rodrigues R, Trindade FG, Cunha M Da, Gomes VM. Thionin-like peptide from Capsicum annuum fruits: Mechanism of action and synergism with fluconazole against Candida species Applied microbiology. BMC Microbiol. 2016; 16: 12.

40. Taveira GB, Mello EO, Andr I, Carvalho O, Regente M, Pinedo M, et al Antimicrobial activity and mechanism of action of a thionin-like peptide from Capsicum annuum fruits and combinatorial treatment with fluconazole against Fusarium solani. Pept Sci. 2017; 108: 23008.

41. Mathews M, Jia HP, Guthmiller JM, Losh G, Graham S, Johnson GK, et al. Production of $\beta$-defensin antimicrobial peptides by the oral mucosa and salivary glands. Infect Immun. 1999; 67: 2740-2745.

42. Krishnakumari $V$, Rangaraj N, Nagaraj R. Antifungal activities of human beta-defensins HBD-1 to HBD-3 and their C-terminal analogs Phd1 to Phd3. Antimicrob Agents Chemother. 2009; 53: 256-260.

43. Basso V, Garcia A, Tran DQ, Schaal JB, Tran P, Ngole D, et al. Fungicidal Potency and Mechanisms of -Defensins against Multidrug-Resistant Candida Species. Antimicrob Agents Chemother. 2018; 62.

44. Han Q, Wu F, Wang X, Qi H, Shi L, Ren A, et al. The bacterial lipopeptide iturins induce Verticillium dahliae cell death by affecting fungal signalling pathways and mediate plant defence responses involved in pathogenassociated molecular pattern-triggered immunity. Environ Microbiol. 2015; 17: 1166-1188.

45. Maget-Dana R, Peypoux F. Iturins, a special class of pore-forming lipopeptides: biological and physicochemical properties. Toxicology. 1994; 87: 151-174

46. Klich MA, Lax AR, Bland JM. Inhibition of some mycotoxigenic fungi by iturin A, a peptidolipid produced by Bacillus subtilis. Mycopathologia. 1991; 116: $77-80$

47. Landy M, Warren GH, Rosenmanm SB, Colio LG. Bacillomycin: An Antibiotic from Bacillus subtilis Active against Pathogenic Fungi. Proc Soc Exp Biol Med. 1948; 67: 539-541.

48. Lei S, Zhao H, Pang B, Qu R, Lian Z, Jiang C, et al. Capability of iturin from Bacillus subtilis to inhibit Candida albicans in vitro and in vivo. Appl Microbiol 
Biotechnol. 2019; 103: 4377-4392

49. Trudel J, Grenier J, Potvin C, Asselin A. Several thaumatin-like proteins bind to $\beta$-1,3-glucans. Plant Physiol. 1998; 118: 1431-1438.

50. Kastuhisa U, Tamio H, Hideyo Y, Fumiyo H, Yoshie Y, Ikunoshin K. Biological Properties Of Aureobasidin A, A Cyclic Depsipeptide Antifungal Antibiotic. J Antibiot (Tokyo). 1993; 46: 1414-1420.

51. Tan HW, Tay ST. The inhibitory effects of aureobasidin A on Candida planktonic and biofilm cells. Mycoses. 2013; 56: 150-156.

52. Zhong W, Jeffries MW, Georgopapadakou NH. Inhibition of inosito phosphorylceramide synthase by aureobasidin A in Candida and Aspergillus species. Antimicrob Agents Chemother. 2000; 44: 651-653.

53. López-Abarrategui C, Alba A, Silva ON, Reyes-Acosta O, Vasconcelos IM Oliveira JTA, et al. Functional characterization of a synthetic hydrophilic antifungal peptide derived from the marine snail Cenchritis muricatus. Biochimie. 2012; 94: 968-974.

54. Vicente FEM, González-Garcia M, Pico ED, Moreno-Castillo E, Garay HE, Rosi PE, et al. Design of a Helical-Stabilized, Cyclic, and Nontoxic Analogue of the Peptide Cm-p5 with Improved Antifungal Activity. ACS Omega. 2019; 4: 19081-19095

55. López-Abarrategui C, McBeth C, Mandal SM, Sun ZJ, Heffron G, AlbaMenéndez A, et al. Cm-p5: An antifungal hydrophilic peptide derived from the coastal mollusk Cenchritis muricatus (Gastropoda: Littorinidae). FASEB J. 2015; 29: 3315-3325.

56. Gow NAR, Latge J-P, Munro CA. The Fungal Cell Wall: Structure, Biosynthesis, and Function. Microbiol Spectr. 2017; 5.

57. Camilli G, Tabouret G, Quintin J. The Complexity of Fungal $\beta$-Glucan in Health and Disease: Effects on the Mononuclear Phagocyte System. Frontiers in Immunology. Frontiers Media S.A. 2018; 9: 673.

58. Bills G, Li Y, Chen L, Yue Q, Niu XM, An Z. New insights into the echinocandins and other fungal non-ribosomal peptides and peptaibiotics. Natural Product Reports. Royal Society of Chemistry. 2014; 31: 1348-1375.

59. Debono M, Abbott Bj, Turner Jr, Howard Lc, Gordee Rs, Hunt As, et al. Synthesis and Evaluation of LY121019, a Member of a Series of Semisynthetic Analogues of the Antifungal Lipopeptide Echinocandin B. Ann N Y Acad Sci. 1988; 544: 152-167

60. Barrett D. From natural products to clinically useful antifungals. Biochimica et Biophysica Acta - Molecular Basis of Disease. Biochim Biophys Acta. 2002; 1587: 224-233.

61. Abruzzo GK, Flattery AM, Gill CJ, Kong L, Smith JG, Pikounis VB, et al. Evaluation of the echinocandin antifungal MK-0991 (L-743,872) Efficacies in mouse models of disseminated aspergillosis, candidiasis, and cryptococcosis. Antimicrob Agents Chemother. 1997; 41: 2333-2338.

62. Bartizal K, Abruzzo G, Trainor C, Krupa D, Nollstadt K, Schmatz D, et al. In vitro antifungal activities and in vivo efficacies of $1,3-\beta$-D-glucan synthesis inhibitors L-671,329, L-646,991, tetrahydroechinocandin B, and L- 687,781, a papulacandin. Antimicrob Agents Chemother. 1992; 36: 1648-1657.

63. Hope WW, Castagnola E, Groll AH, Roilides E, Akova M, Arendrup MC, et al ESCMID guideline for the diagnosis and management of Candida diseases 2012: Prevention and management of invasive infections in neonates and children caused by Candida spp. Clin Microbiol Infect. 2012; 18: 38-52.

64. Cornely OA, Bassetti M, Calandra T, Garbino J, Kullberg BJ, Lortholary $\mathrm{O}$, et al. ESCMID guideline for the diagnosis and management of Candida diseases 2012: Non-neutropenic adult patients. Clin Microbiol Infect. 2012 18: 19-37.

65. Lenardon MD, Munro CA, Gow NAR. Chitin synthesis and fungal pathogenesis. Current Opinion in Microbiology. 2010; 13: 416-423.

66. Latgé JP. The cell wall: A carbohydrate armour for the fungal cell. Molecular Microbiology. Mol Microbiol. 2007; 66: 279-290.

67. Klis FM, Boorsma A, Groot PWJ De. Cell wall construction in Saccharomyces cerevisiae. Yeast. Yeast; 2006; 23: 185-202.
68. Lee KK, MacCallum DM, Jacobsen MD, Walker LA, Odds FC, Gow NAR, et al. Elevated cell wall chitin in Candida albicans confers echinocandin resistance in vivo. Antimicrob Agents Chemother. 2012; 56: 208-217.

69. Stenland CJ, Lis LG, Schendel FJ, Hahn NJ, Smart MA, Miller AL, et al. A practical and scalable manufacturing process for an antifungal agent, nikkomycin Z. Org Process Res Dev. 2013; 17: 265-272.

70. Hector RF, Zimmer BL, Pappagianis D. Evaluation of Nikkomycins X and Z in murine models of coccidioidomycosis, histoplasmosis, and blastomycosis. Antimicrob Agents Chemother. 1990; 34: 587-593

71. Goldberg J, Connolly P, Schnizlein-Bick C, Durkin M, Kohler S, Smedema $\mathrm{M}$, et al. Comparison of nikkomycin Z with amphotericin B and itraconazole for treatment of histoplasmosis in a murine model. Antimicrob Agents Chemother. 2000; 44: 1624-1629.

72. Clemons KV, Stevens DA. Efficacy of nikkomycin Z against experimenta pulmonary blastomycosis. Antimicrob Agents Chemother. 1997; 41: 20262028.

73. Ganesan LT, Manavathu EK, Cutright JL, Alangaden GJ, Chandrasekar $\mathrm{PH}$. In-vitro activity of nikkomycin Z alone and in combination with polyenes, triazoles or echinocandins against Aspergillus fumigatus. Clin Microbio Infect. 2004; 10: 961-966.

74. Chiou CC, Mavrogiorgos N, Tillem E, Hector R, Walsh TJ. Synergy, pharmacodynamics, and time-sequenced ultrastructural changes of the interaction between nikkomycin Z and the echinocandin FK463 against Aspergillus fumigatus. Antimicrob Agents Chemother. 2001; 45: 3310-3321.

75. Kovács R, Nagy F, Tóth Z, Bozó A, Balázs B, Majoros L. Synergistic effect of nikkomycin $Z$ with caspofungin and micafungin against Candida albicans and Candida parapsilosis biofilms. Lett Appl Microbiol. 2019; 69: 71-78.

76. Kim MK, Park HS, Kim CH, Park HM, Choi W. Inhibitory effect of nikkomycin Z on chitin synthases in Candida albicans. Yeast. 2002; 19: 341-349.

77. Segal E, Gottlieb S, Altboum Z, Gov Y, Berdicevsky I. Adhesion of candida albicans to epithelial cells - Effect of nikkomycin. Mycoses. 1997; 40: 33-39.

78. Osada H. Discovery and applications of nucleoside antibiotics beyond polyoxin [Internet]. Journal of Antibiotics. Nature Publishing Group. 2019; 72: 855-864.

79. Becker JM, Covert NL, Shenbagamurthi P, Steinfeld AS, Naider F. Polyoxin $D$ inhibits growth of zoopathogenic fungi. Antimicrob Agents Chemother. 1983; 23: 926-929.

80. Levitz SM, Selsted ME, Ganz T, Lehrer RI, Diamond RD, Levitz SM, et al. In vitro killing of spores and hyphae of aspergillus fumigatus and rhizopus oryzae by rabbit neutrophil cationic peptides and bronchoalveolar macrophages. J Infect Dis. 1986; 154: 483-489.

81. Segal GP, Lehrer RI, Selsted ME. In vitro effect of phagocyte cationic peptides on coccidioides immitis. J Infect Dis. 1985; 151: 890-894.

82. Selsted ME, Szklarek D, Ganz T, Lehrer RI. Activity of rabbit leukocyte peptides against Candida albicans. Infect Immun. 1985; 49: 202-206.

83. Hall RA, Gow NAR. Mannosylation in candida albicans: Role in cell wall function and immune recognition. Molecular Microbiology. Mol Microbiol. 2013; 90: 1147-1161.

84. Prill S, Klinkert B, Al E. (PDF) PMT family of Candida albicans: five protein mannosyltransferase isoforms affect growth, morphogenesis and antifungal resistance | Birgit Klinkert and Cheryl Gale - Academia.edu. 2005; 55: 546560.

85. Timpel C, Zink S, Strahl-Bolsinger S, Schröppel K, Ernst J. Morphogenesis, adhesive properties, and antifungal resistance depend on the Pmt6 protein mannosyltransferase in the fungal pathogen Candida albicans. J Bacteriol. 2000; 182: 3063-3071.

86. Oki T, Tenmyo O, Hlrano M, Tomatsu K, Kamei H. Pradimicins A, B and C: New antifungal antibiotics. II. In vitro and in vivo biological activities. J Antibiot (Tokyo). 1990; 43: 763-770.

87. Tomokazu U, Keilchi N, Yosuke S, Tasuku N, Yasuo F, Toshikazu O. Studies on the Mode of Antifungal Action of Pradimicin Antibiotics I. Lectin- 
Mimic Binding of BMY-28864 to Yeast Mannan in the Presence of Calcium J Antibiot (Tokyo). 1993; 46: 149-161.

88. Nakagawa $\mathrm{Y}$, Doi T, Takegoshi K, Sugahara T, Akase D, Aida M, et al Molecular Basis of Mannose Recognition by Pradimicins and their Application to Microbial Cell Surface Imaging. Cell Chem Biol. 2019; 26: 950-959.e8.

89. Uyterhoeven ET, Butler CH, Ko D, Elmore DE. Investigating the nucleic acid interactions and antimicrobial mechanism of buforin II. FEBS Lett. 2008; 582: $1715-1718$

90. Cho JH, Sung BH, Kim SC. Buforins: Histone H2A-derived antimicrobia peptides from toad stomach. Biochimica et Biophysica Acta - Biomembranes. Elsevier. 2009; 1788: 1564-1569.

91. Rathod BB, Korasapati R, Sripadi P, Shetty PR. Novel actinomycin group compound from newly isolated Streptomyces sp. RAB12: isolation, characterization, and evaluation of antimicrobial potential. Appl Microbio Biotechnol. 2018; 102:1241-1250.

92. Ortega E, Algarra I, Serrano MJ, Cienfuegos GA De, Gaforio JJ. The use of 7-amino-actinomycin $D$ in the analysis of Candida albicans phagocytosis and opsonization. J Immunol Methods. 2001; 253: 189-193.

93. Marchand C, Krajewski K, Lee HF, Antony S, Johnson AA, Amin R, et al. Covalent binding of the natural antimicrobial peptide indolicidin to DNA abasic sites. Nucleic Acids Res. 2006; 34: 5157-5165.

94. Subbalakshmi C, Sitaram N. Mechanism of antimicrobial action of indolicidin FEMS Microbiol Lett. 1998; 160: 91-96.

95. Zanetti M. Cathelicidins, multifunctional peptides of the innate immunity. $J$ Leukoc Biol. 2004; 75: 39-48.

96. Bahar AA, Ren D. Antimicrobial peptides. Pharmaceuticals. MDPI AG. 2013; 6: 1543-1575

97. Dehsorkhi A, Castelletto V, Hamley IW. Self-assembling amphiphilic peptides. In: Journal of Peptide Science. John Wiley and Sons Ltd. 2014 20: 453-467.

98. Kim JY, Park SC, Kim MH, Lim HT, Park Y, Hahm KS. Antimicrobial activity studies on a trypsin-chymotrypsin protease inhibitor obtained from potato. Biochem Biophys Res Commun. 2005; 330: 921-927.

99. Raguse TL, Porter EA, Weisblum B, Gellman SH. Structure - Activity studies of 14-helical antimicrobial $\beta$-peptides: Probing the relationship between conformational stability and antimicrobial potency. J Am Chem Soc. 2002 124: $12774-12785$.

100.Lee DL, Hodges RS. Structure-activity relationships of de novo designed cyclic antimicrobial peptides based on gramicidin S. In: Biopolymers Peptide Science Section. Biopolymers. 2003; 71: 28-48.

101. Eckert R, Qi F, Yarbrough DK, He J, Anderson MH, Shi W. Adding selectivity to antimicrobial peptides: Rational design of a multidomain peptide agains Pseudomonas spp. Antimicrob Agents Chemother. 2006; 50: 1480-1488.

102. Bommarius B, Jenssen $\mathrm{H}$, Elliott M, Kindrachuk J, Pasupuleti M, Gieren $\mathrm{H}$, et al. Cost-effective expression and purification of antimicrobial and hos defense peptides in Escherichia coli. Peptides. 2010; 31: 1957-1965.

103. Bagheri M, Beyermann M, Dathe M. Immobilization reduces the activity of surface-bound cationic antimicrobial peptides with no influence upon the activity spectrum. Antimicrob Agents Chemother. 2009; 53: 1132-1141.

104. Jiang Z, Vasil AI, Hale JD, Hancock REW, Vasil ML, Hodges RS. Effects of net charge and the number of positively charged residues on the biological activity of amphipathic $\alpha$-helical cationic antimicrobial peptides. Biopolym Pept Sci Sect. 2008; 90: 369-383.

105. Westerhoff HV, Juretic D, Hendler RW, Zasloff M. Magainins and the disruption of membrane-linked free-energy transduction. Proc Natl Acad Sci U S A. 1989; 86: 6597-6601.

106. Lee MR, Raman N, Gellman SH, Lynn DM, Palecek SP. Hydrophobicity and helicity regulate the antifungal activity of 14 -helical $\beta$-peptides. ACS Chem Biol. 2014; 9: 1613-1621.

107.Papo N, Oren Z, Pag U, Sahl HG, Shai Y. The consequence of sequence alteration of an amphipathic $\alpha$-helical antimicrobial peptide and its diastereomers. J Biol Chem. 2002; 277: 33913-23391.

108. Pace CN, Scholtz JM. A helix propensity scale based on experimental studies of peptides and proteins. Biophys J. 1998; 75: 422-427.

109. Huang Y, Huang J, Chen Y. Alpha-helical cationic antimicrobial peptides: Relationships of structure and function. Protein and Cell. Higher Education Press. 2010; 1: 143-152.

110. Chen L, Harrison SD. Cell-penetrating peptides in drug development: Enabling intracellular targets. In: Biochemical Society Transactions. Portland Press Ltd. 2007; 35: 821-825.

111. Zelezetsky I, Pacor S, Pag U, Papo N, Shai Y, Sahl HG, et al. Controlled alteration of the shape and conformational stability of a-helical cell-lytic peptides: Effect on mode of action and cell specificity. Biochem J. 2005; 390: 177-188.

112. Kustanovich I, Shalev DE, Mikhlin M, Gaidukov L, Mor A. Structural requirements for potent versus selective cytotoxicity for antimicrobial dermaseptin S4 derivatives. J Biol Chem. 2002; 277: 16941-16951.

113. Fernández-Vidal $M$, Jayasinghe $S$, Ladokhin AS, White SH. Folding Amphipathic Helices into Membranes: Amphiphilicity Trumps Hydrophobicity. J Mol Biol. 2007; 370: 459-470

114. Wiradharma N, Sng MYS, Khan M, Ong ZY, Yang YY. Rationally designed a-helical broad-spectrum antimicrobial peptides with idealized facial amphiphilicity. Macromol Rapid Commun. 2013; 34: 74-80.

115. Khara JS, Obuobi S, Wang Y, Hamilton MS, Robertson BD, Newton SM, et al. Disruption of drug-resistant biofilms using de novo designed short a-helical antimicrobial peptides with idealized facial amphiphilicity. Acta Biomater. 2017; 57: 103-114.

116. Hollmann A, Martinez M, ME N. Role of amphipathicity and hydrophobicity in the balance between hemolysis and peptide-membrane interactions of three related antimicrobial peptides. Colloids Surf B Biointerfaces. 2016; 141: 528-536.

117. Wang J, Chou S, Yang Z, Yang Y, Wang Z, Song J, et al. Combating DrugResistant Fungi with Novel Imperfectly Amphipathic Palindromic Peptides. J Med Chem. 2018; 61: 3889-3907.

118. Szekeres A, Leitgeb B, Kredics L, Antal Z, Hatvani L, Manczinger L, et al. Peptaibols and related peptaibiotics of Trichoderma: A review. In: Acta Microbiologica et Immunologica Hungarica. Akadémiai Kiadó. 2005; 52: 137-168.

119. Zhao P, Xue Y, Li X, Li J, Zhao Z, Quan C, et al. Fungi-derived lipopeptide antibiotics developed since 2000. Peptides. Elsevier Inc. 2019; 113: 52-65.

120. Ishiyama D, Satou T, Senda H, Fujimaki T, Honda R, Kanazawa S. Heptaibin, a novel antifungal peptaibol antibiotic from Emericellopsis sp. BAUA8289. Journal of Antibiotics. Japan Antibiotics Research Association. 2000; 53: 728-732.

121. DeLucca AJ, Bland JM, Jacks TJ, Grimm C, Cleveland TE, Walsh TJ. Fungicidal activity of cecropin A. Antimicrob Agents Chemother. 1997; 41: 481-483.

122. den Hertog AL, van Marle .undefined. Candidacidal effects of two antimicrobial peptides: histatin 5 causes small membrane defects, but LL37 causes massive disruption of the cell membrane. Biochemical J. 2005; 388: 689-695.

123. Galloo RL, Kim KJ, Bernfield M, Kozak CA, Zanetti M, Merluzzi L, et al. Identification of CRAMP, a cathelin-related antimicrobial peptide expressed in the embryonic and adult mouse. J Biol Chem. 1997; 272: 13088-13093.

124. Oh SU, Yun BS, Lee SJ, Kim JH, Yoo ID. Atroviridins A-C and neoatroviridins A-D, novel peptaibol antibiotics produced by Trichoderma atroviride F80317. I. Taxonomy, fermentation, isolation and biological activities. J Antibiot (Tokyo). 2002; 55: 557-564.

125. Summers MY, Kong F, Feng X, Siegel MM, Janso JE, Graziani El, et al. Septocylindrins $A$ and $B$ : Peptaibols produced by the terrestrial fungus Septocylindrium sp. LL-Z1518. J Nat Prod. 2007; 70: 391-396. 
126. Vouldoukis I, Shai $Y$, Nicolas $P$, Mor A. Broad spectrum antibiotic activity of skin-PYY. FEBS Lett. 1996; 380: 237-240.

127. Mor A, Chartrel N, Vaudry $H$, Nicolas $P$. Skin peptide tyrosine-tyrosine, a member of the pancreatic polypeptide family: Isolation, structure, synthesis, and endocrine activity. Proc Natl Acad Sci U S A. 1994; 91: 10295-10299.

128. Park Y, Park SC, Park HK, Shin SY, Kim Y, Hahm KS. Structure-activity relationship of HP (2-20) analog peptide: Enhanced antimicrobial activity by $\mathrm{N}$-terminal random coil region deletion. In: Biopolymers - Peptide Science Section. Biopolymers. 2007; 88: 199-207.

129. Lee DG, Park Y, Kim HN, Kim HK, Kim P II, Choi BH, et al. Antifungal mechanism of an antimicrobial peptide, HP (2-20), derived from $\mathrm{N}$-terminus of Helicobacter pylori Ribosomal Protein L1 against Candida albicans. Biochem Biophys Res Commun. 2002; 291: 1006-1013.

130. Kakiki K, Misato T, Hori M, Eguchi J. Studies on the mode of action of polyoxins. VI: Effect of polyoxin $b$ on chitin synthesis in polyoxin-sensitive and resistant strains of alternaria kikuchiana. J Antibiot (Tokyo). 1974; 27: 260-266.

131. Song B, Rong YJ, Zhao MX, Chi ZM. Antifungal activity of the lipopeptides produced by Bacillus amyloliquefaciens anti-CA against Candida albicans isolated from clinic. Appl Microbiol Biotechnol. 2013; 97: 7141-7150.

132. Tao Y, mei Bie X, xia Lv F, zhen Zhao H, xin Lu Z. Antifungal Activity and Mechanism of Fengycin in the Presence and Absence of Commercia Surfactin Against Rhizopus Stolonifer. J Microbiol. 2011; 49: 146-150.

133. Krishnan N, Velramar B, Velu RK. Investigation of antifungal activity of surfactin against mycotoxigenic phytopathogenic fungus Fusarium moniliforme and its impact in seed germination and mycotoxicosis. Pestic Biochem Physiol. 2019; 155: 101-107.

134. Kolaczkowska A, Kolaczkowski M, Sokolowska A, Miecznikowska $H$ Kubiak A, Rolka K, et al. The antifungal properties of chicken egg cystatin against Candida yeast isolates showing different levels of azole resistance. Mycoses. 2010; 53: 314-320.

135. Guzmán-de-Peña DL, Correa-González AM, Valdés-Santiago L, LeónRamírez CG, Valdés-Rodríguez S. In vitro effect of recombinant amaranth cystatin (AhCPI) on spore germination, mycelial growth, stress response and cellular integrity of Aspergillus niger and Aspergillus parasiticus. Mycology. 2015; 6: 168-175

136. Rinanda T. Rinanda T. In Silico Studies in Antimicrobial Peptides Design and Development. IOP Conference Series: Earth and Environmental Science, IOP Publishing - Google Search. 2019; 305: 12062

137. Roy A, Nair S, Sen N, Soni N, Madhusudhan MS. In silico methods for design of biological therapeutics. Methods. 2017; 131: 33-65.

138. Ke T, Cao H, Huang J, Hu F, Huang J, Dong C, et al. EST-based in silico identification and in vitro test of antimicrobial peptides in Brassica napus. BMC Genomics. 2015; 16: 653.

139. Thomas S, Karnik S, Barai RS, Jayaraman VK, Idicula-Thomas S. CAMP: A useful resource for research on antimicrobial peptides. Nucleic Acids Res. 2009; 38: 774-780.

140.Zhao X, Wu H, Lu H, Li G, Huang Q. LAMP: A Database Linking Antimicrobial Peptides. PLoS One. 2013; 8: e66557.

141.Gogoladze G, Grigolava M, Vishnepolsky B, Chubinidze M, Duroux P Lefranc MP, et al. DBAASP: Database of antimicrobial activity and structure of peptides. FEMS Microbiol Lett. 2014; 357: 63-68.

142. Fjell CD, Hancock REW, Cherkasov A. AMPer: A database and an automated discovery tool for antimicrobial peptides. Bioinformatics. 2007; 23: $1148-1155$.

143. Fh W, L G, Rs B, P R, B N, S I-T. CAMP: Collection of sequences and structures of antimicrobial peptides. Nucleic Acids Res. 2014; 42.1154-1158.

144.Wang G, Li X, Wang Z. APD3: The antimicrobial peptide database as a tool for research and education. Nucleic Acids Res. 2016; 44: D1087-1093.

145. Fan L, Sun J, Zhou M, Zhou J, Lao X, Zheng H, et al. DRAMP: a comprehensive data repository of antimicrobial peptides. Sci Reports. 2016;
6: 24482 .

146. S L, L F, J S, X L, H Z. Computational resources and tools for antimicrobial peptides. J Pept Sci. 2017; 23: 4-12.

147. Piotto SP, Sessa L, Concilio S, lannelli P. YADAMP: Yet another database of antimicrobial peptides. Int J Antimicrob Agents. 2012; 39: 346-351.

148. Wang G, Li X, Wang Z. APD3: The antimicrobial peptide database as a too for research and education. Nucleic Acids Res. 2016; 44: D1087-1093.

149. Wang G, Li X, Wang Z. APD2: The updated antimicrobial peptide database and its application in peptide design. Nucleic Acids Res. 2009; 37: 933-937.

150. Maccari G, Di Luca M, Nifosì R. In Silico Design of Antimicrobial Peptides. Computational Peptidology. 2014; 1268: 195-219.

151. Robinson JA. Protein epitope mimetics as anti-infectives. Current Opinion in Chemical Biology.2011; 15: 379-386.

152. Wiradharma N, Khoe U, Hauser CAE, Seow SV, Zhang S, Yang YY Synthetic cationic amphiphilic a-helical peptides as antimicrobial agents. Biomaterials. 2011; 32: 2204-2212.

153. Pag U, Oedenkoven M, Sass V, Shai Y, Shamova O, Antcheva N, et al. Analysis of in vitro activities and modes of action of synthetic antimicrobial peptides derived from an $\alpha$-helical "sequence template." J Antimicrob Chemother. 2008; 61.341-352

154. Fiell CD, Hiss JA, Hancock REW, Schneider G. Designing antimicrobia peptides: Form follows function. Nature Reviews Drug Discovery. Nature Publishing Group. 2012; 11: 37-51.

155. Jiang Z, Vasil AI, Gera L, Vasil ML, Hodges RS. Rational Design of a-Helical Antimicrobial Peptides to Target Gram-negative Pathogens, Acinetobacter baumannii and Pseudomonas aeruginosa: Utilization of Charge, "Specificity Determinants," Total Hydrophobicity, Hydrophobe Type and Location as Design Parameters to Improve the Therapeutic Ratio. Chem Biol Drug Des. $2011 ; 77: 225-240$

156.Wang Q, Hong G, Johnson GR, Pachter R, Cheung MS. Biophysical properties of membrane-active peptides based on micelle modeling: A case study of cell-penetrating and antimicrobial peptides. J Phys Chem B. 2010; 114: 13726-13735

157. J. Bond P, Khalid S. Antimicrobial and Cell-Penetrating Peptides: Structure, Assembly and Mechanisms of Membrane Lysis via Atomistic and CoarseGrained Molecular Dynamic Simulations. Protein Pept Lett. 2012; 17: 13131327.

158. Sengupta D, Leontiadou H, Mark AE, Marrink SJ. Toroidal pores formed by antimicrobial peptides show significant disorder. Biochim Biophys Acta Biomembr. 2008; 1778: 2308-2317.

159. Khandelia H, Kaznessis YN. Molecular dynamics simulations of helical antimicrobial peptides in SDS micelles: What do point mutations achieve? Peptides. 2005; 26: 2037-2049.

160. Tsai CW, Hsu NY, Wang CH, Lu CY, Chang Y, Tsai HHG, et al. Coupling Molecular Dynamics Simulations with Experiments for the Rational Design of Indolicidin-Analogous Antimicrobial Peptides. J Mol Biol. 2009; 392: 837854.

161.Pande J, Szewczyk MM, Grover AK. Phage display: Concept, innovations, applications and future. Biotechnology Advances. Biotechnol Adv. 2010; 28 849-858.

162. Schneider G, Böhm HJ. Virtual screening and fast automated docking methods. Drug Discovery Today. Elsevier Ltd. 2002; 7: 64-70.

163. Schneider G. Molecular Design: Concepts and Applications. Wiley. 2008; 277.

164. Schneider G. Basic overview of chemoinformatics. Journal of Chemical Information and Modeling. J Chem Inf Model. 2002; 46: 2267-2277.

165. Wang P, Hu L, Liu G, Jiang N, Chen X, Xu J, et al. Prediction of Antimicrobial Peptides Based on Sequence Alignment and Feature Selection Methods. PLoS One. 2011; 6: e18476.

166. Naresh E, Vijaya Kumar, Ayesha, Shankar SP. Impact of Machine Learning 
in Bioinformatics Research. 2020; 41-62.

167.X X, P W, WZ L, JH J, KC C. iAMP-2L: a two-level multi-label classifier for identifying antimicrobial peptides and their functional types. Anal Biochem. 2013; 436: 168-177.

168. Kliger Y. Computational approaches to therapeutic peptide discovery Biopolymers. 2010; 94: 701-710.

169. Hiss JA, Hartenfeller M, Schneider G. Concepts and Applications of \&\#x201C; Natural Computing\&\#x201D; Techniques in De Novo Drug and Peptide Design. Curr Pharm Des. 2010; 16: 1656-1665.

170. Hohm T, Limbourg P, Hoffmann D. A multiobjective evolutionary method for the design of peptidic mimotopes. J Comput Biol. 2006; 13: 113-125.

171.Gómez-Bombarelli R, Wei JN, Duvenaud D, Hernández-Lobato JM Sánchez-Lengeling $B$, Sheberla $D$, et al. Automatic Chemical Design Using a Data-Driven Continuous Representation of Molecules. ACS Cent Sci. 2018; 4: 268-276.

172. Puentes PR, Henao MC, Torres CE, Gómez SC, Gómez LA, Burgos JC et al. Design, screening, and testing of non-rational peptide libraries with antimicrobial activity: In silico and experimental approaches. Antibiotics. MDPI AG. 2020; 9: 854

173. Lan Y. Early Warning for Infectious Disease Outbreak. Early Warning fo Infectious Disease Outbreak. Elsevier. 2017.

174.Fjell CD, Hancock REW, Cherkasov A. AMPer: A database and an automated discovery tool for antimicrobial peptides. Bioinformatics. 2007 23: 1148-1155.

175. Madera M. research JG-N acids, undefined. A comparison of profile hidden Markov model procedures for remote homology detection. 2002; 30: 4321 4328

176.Borah A, Deb B, Chakraborty S. A Crosstalk on Antimicrobial Peptides. International Journal of Peptide Research and Therapeutics. Springer Science and Business Media B.V. 2021; 27: 229-244.

177. Gautam A, Chaudhary K, Kumar R, Raghava GPS. Computer-aided virtual screening and designing of cell-penetrating peptides. Cell-Penetrating Peptides: Methods and Protocols. Springer New York. 2015; 59-69.

178. Sharma A, Gupta P, Kumar R, Bhardwaj A. DPABBs: A Novel in silico Approach for Predicting and Designing Anti-biofilm Peptides. Sci Rep. 2016 6: 21839.
179. Boman HG. Antibacterial peptides: Basic facts and emerging concepts. Journal of Internal Medicine. J Intern Med. 2003; 254: 197-215.

180.Wang G, Li X, Wang Z. APD2: The updated antimicrobial peptide database and its application in peptide design. Nucleic Acids Res. 2009; 37: 933-937.

181. Gasteiger E, Hoogland C, Gattiker A, Duvaud S, Wilkins MR, Appel RD, et al. Protein Identification and Analysis Tools on the ExPASy Server. The Proteomics Protocols Handbook. Humana Press. 2005; 571-607.

182. Sharma A, Singla D, Rashid M, Raghava GPS. Designing of peptides with desired half-life in intestine-like environment. BMC Bioinformatics. 2014; 15 : 282.

183. Meher PK, Sahu TK, Rao AR. Prediction of donor splice sites using random forest with a new sequence encoding approach. BioData Min. 2016; 9: 1-25.

184. Chaudhary K, Kumar R, Singh S, Tuknait A, Gautam A, Mathur D, et al. A web server and mobile app for computing hemolytic potency of peptides. Sci Rep. 2016; 6: 22843.

185. Gupta S, Kapoor P, Chaudhary K, Gautam A, Kumar R, Raghava GPS. In Silico Approach for Predicting Toxicity of Peptides and Proteins. PLoS One. 2013; 8: e73957.

186. Molero-Abraham M, Glutting JP, Flower DR, Lafuente EM, Reche PA EPIPOX: Immunoinformatic Characterization of the Shared T-Cell Epitome between Variola Virus and Related Pathogenic Orthopoxviruses. J Immunol Res. 2015; 2015: 738020 .

187. Thévenet $\mathrm{P}$, Shen $\mathrm{Y}$, Maupetit J, Guyon F, Derreumaux $\mathrm{P}$, Tufféry P. PEPFOLD: An updated de novo structure prediction server for both linear and disulfide bonded cyclic peptides. Nucleic Acids Res. 2012; 40: W288-W293.

188. Lovell SC, Davis IW, Arendall WB, Bakker PIW De, Word JM, Prisant MG et al. Structure validation by $C \alpha$ geometry: $\varphi, \psi$ and $C \beta$ deviation. Proteins Struct Funct Genet. 2003; 50: 437-450.

189. Fjell CD, Jenssen $H$, Fries $P$, Aich $P$, Griebel $P$, Hilpert $K$, et al. Identification of novel host defense peptides and the absence of $\alpha$-defensins in the bovine genome. Proteins Struct Funct Genet. 2008; 73: 420-430.

190. Divyashree M, Mani MK, Reddy D, Kumavath R, Ghosh P, Azevedo V, et al Clinical Applications of Antimicrobial Peptides (AMPs): Where do we Stand Now? Protein Pept Lett. 2019; 27: 120-134 